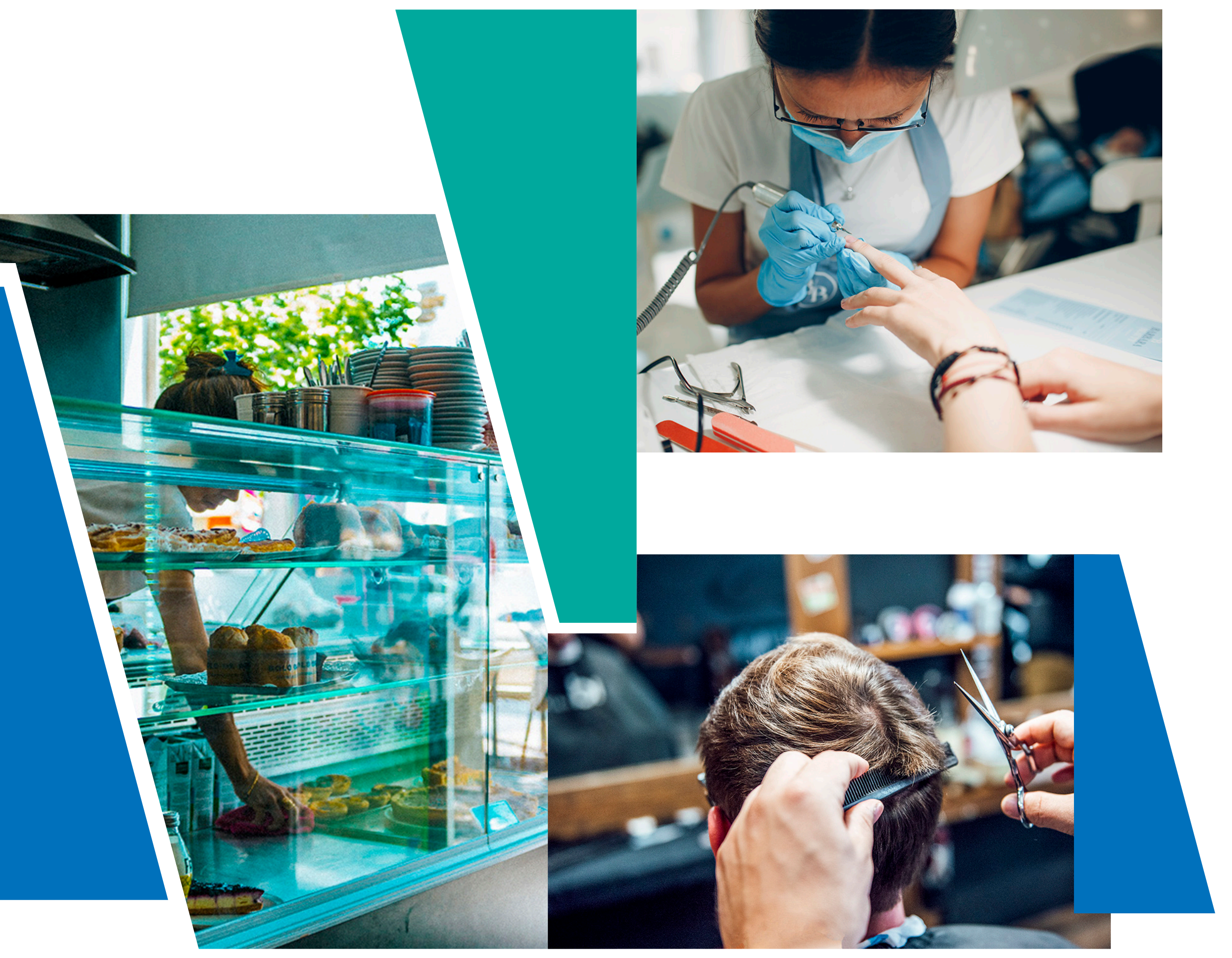

\title{
IMPACTO ECONÓMICO \\ DE LA CRISIS COVID-19 \\ SOBRE LA MIPYME EN MÉXICO
}

Lucio Jesús Uc Heredia

Domingo García Pérez de Lema (Coordinadores)

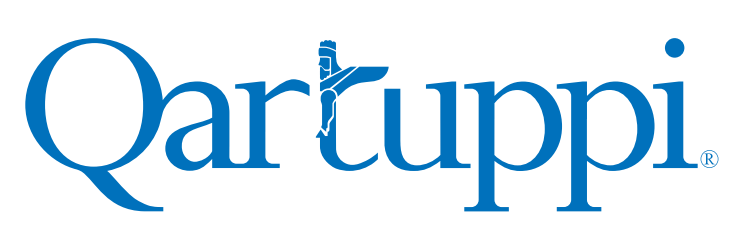




\section{(c) (i) () ()}

Esta obra se edita bajo una Licencia Creative Commons Atribución-NoComercial-Compartirlgual 4.0 Internacional. 
Coordinadores

Lucio Jesús Uc Heredia

Domingo García Pérez de Lema

Autores

Luis Enrique Ibarra Morales

Héctor Horacio Garza Sánchez

Acasia Molina Solís

Alejandra López Salazar

Lucio Jesús Uc Heredia

Blanca Estela Bernal Escoto

Luis Enrique Valdez Juárez

IMPACTO ECONÓMICO DE LA CRISIS COVID-19

SOBRE LA MIPYME EN MÉXICO

1era. edición, diciembre 2021

ISBN 978-607-8694-23-5

DOI 10.29410/QTP.21.19

D.R. (C) 2021. Qartuppi, S. de R.L. de C.V. Villa Turca 17, Villas del Mediterráneo Hermosillo, Son. 83220 México https://qartuppi.com

Edición: Qartuppi, S. de R.L. de C.V.

Diseño editorial: Catalina Guiffo Cardona

Fotografía: Unsplash / Scopio 
Equipo de investigación FAEDPYME

Universidad Autónoma de Baja California

Blanca Estela Bernal Escoto

Nancy Imelda Montero Delgado

Flavio Abel Rivera Aguirre

Universidad de Guanajuato

(Campus Celaya-Salvatierra)

Alejandra López Salazar

Rubén Molina Sánchez

Gloria Leticia López Salaza

Roberto Godínez López

Alba María del Carmen González Vega

Universidad Autónoma de Nuevo León

Héctor Horacio Garza Sánchez

Martha del Pilar Rodríguez García

Margarita Amada Ponce González

Universidad Tecnológica

de Tamaulipas Norte

Acasia Molina Solís

Víctor Manuel Martínez Rocha

Sanjuana Guadalupe De León Zapata
Universidad Estatal de Sonora

(Unidad Académica Hermosillo)

Luis Enrique Ibarra Morales

Emma Vanessa Casas Medina

Daniel Paredes Zempual

Esthela Carrillo Cisneros

Erika Olivas Valdez

Instituto Tecnológico de Sonora

Luis Enrique Valdez Juárez

Elva Alicia Ramos Escobar

Edith Patricia Borboa Alvarez

Irma Guadalupe Esparza García

Luis Fernando Olachea Parra

José Alonso Ruiz Zamora

Universidad Autónoma de Yucatán

Lucio Jesús Uc Heredia

Laura Guillermina Duarte Cáceres

Víctor Manuel Villasuso Pino

Lilia Carolina Avilés Heredia

Idalia Amparo De los Santos Briones 


\section{Equipos colaboradores}

Universidad Autónoma de Coahuila

Víctor Manuel Molina Morejón

Víctor Manuel Solís Cardoza

Hugo Villarroel Pantoja

Jesús Gerardo Morales Rivas

Alma Josefina Chapa Martínez

Gabriela Leticia González Sánchez

Junior Enrique Jara Flores

María Dolores Estrada García

Eunice Ocaña De La Cruz

Universidad Politécnica de Guanajuato

Sandra Téllez Vázquez

Joel Curtidor Santana

Susana Eugenia Villegas Femat

Universidad Autónoma

del Estado de Hidalgo

(Escuela Superior Tepeji del Rio)

Magda Gabriela Sánchez Trujillo

Universidad de Quintana Roo

Francisco Javier Güemez Ricalde
Universidad Popular Autónoma

del Estado de Puebla

Ingrid Pinto López

Cynthia Montaudon Tomas

Yesica Mayett Moreno

Universidad Autónoma de Ciudad Juárez

Andrea Yelvani Salazar Ibarra

Bibiana Cazares Romero

Universidad Juárez Autónoma de Tabasco

Jesús Chan Hernández

José Luis Hernández Juárez

Lourdes Baeza Mendoza

Blanca Alicia Sánchez Ruiz

Hardy Francisco Platas Rodríguez

Universidad Politécnica de Victoria

Víctor Manuel Martínez Rocha

Estela Torres Ramírez

Daniela Cruz Delgado

Julio César García Martínez 
Impacto económico de la crisis COVID-19 sobre la MIPYME en México es el resultado de una iniciativa del Observatorio Iberoamericano de la micro, pequeña y mediana empresa (MIPYME), cuyo objeto principal es suministrar información continuada de las estrategias y expectativas de las empresas para facilitar y apoyar la toma de decisiones, principalmente en el ámbito económico y estratégico. En este proyecto, todos los informes realizados en los diferentes países siguen los mismos patrones de formato, estructura y metodología, con el objetivo de homogeneizar los resultados y comparabilidad. El observatorio es una estrategia de la Alianza Interredes para la cooperación académica entre la Red Universitaria de Emprendimiento (REUNE) de la Asociación Colombiana de Universidades (ASCUN), la Fundación para el Análisis Estratégico y Desarrollo de la PYME (FAEDPYME), la Red Latinoamericana de innovación y Emprendimiento (RLIE) del Consejo Latinoamericano de Escuelas de Administración (CLADEA) y la Red Universitaria Iberoamericana sobre Creación de Empresas y Emprendimiento (RED MOTIVA). 


\section{Contenido}

1. Introducción

2. Metodología de la investigación 11

2.1. Estructura de la muestra 11

2.2. Selección de variables y diseño del cuestionario $\quad 13$

2.3. Análisis estadístico de los datos 14

3. Datos generales de las empresas 15

4. Impacto económico 19

4.1. Empleo 19

4.2. Ventas 24

4.3. Indicadores económicos y financieros 30

4.4. Internacionalización $\quad 35$

5. Impacto sobre la organización de la empresa 38

5.1. Actividades con clientes y proveedores 38

5.2. Actividades operativas 41

5.3. Actividades estratégicas 43

6. Actividad innovadora 46

7. Acceso al financiamiento 54

8. Indicadores de rendimiento 63

9. Resumen ejecutivo 66

$\begin{array}{ll}\text { 10. Referencias } & 72\end{array}$ 


\section{Introducción}

Ante la pandemia por Covid-19, en México y en el mundo se ha generado un fuerte impacto sanitario, social y económico. La contingencia sanitaria ha afectado a muchas empresas y ha provocado el surgimiento de fuertes tensiones que pueden limitar su competitividad y su supervivencia. La Comisión Económica para América y el Caribe (CEPAL) identificó algunos efectos que podían ocurrir en las economías globales: (a) efectos graves en la oferta y demanda a nivel agregado y sectorial; (b) interrupción y desaceleración de la producción; (c) afectación a los mercados globales (falta de confianza, deterioro de cadenas globales); (d) caída de la tasa de crecimiento de la economía mundial; (e) problemas financieros a nivel macroeconómico causado por la baja de consumo, las pérdidas por paralización de plantas y todos los problemas que eso causa, los atrasos en pagos, la pérdida de rentabilidad y las quiebras generalizadas; (f) falta de liquidez, un mayor endeudamiento y una desaceleración de la economía en general (CEPAL, 2020). Todo esto ha propiciado una reducción de la actividad económica, que se ha visto reflejada en el mercado laboral, incrementando el desempleo. Adicionalmente, la COVID-19 es un caso único debido a la velocidad de propagación en el mundo, que ha causando estragos en la economía global (Sharma et al., 2020). 
Actualmente, muchas instituciones están trabajando para establecer estrategias de reactivación económica con el ánimo de mitigar los impactos generados por la pandemia de CovID-19. En el camino hacia una recuperación fuerte y sostenible, será necesario establecer políticas en el corto, mediano y largo plazo que aumenten las perspectivas de crecimiento (Banco Mundial, 2021). La severidad de los efectos de la crisis dependerá de las condiciones en las que cada estado o municipio y el país en general se encuentre, así como de los aciertos o desaciertos de las medidas adoptadas por sus respectivos gobiernos. Por lo tanto, resulta imprescindible disponer de información, cuantitativa y cualitativa, del comportamiento de las empresas ante los efectos económicos de la Covid-19. Esto permitirá conocer las necesidades y los desequilibrios que puedan producirse y, de esta manera, gestionar eficientemente los recursos para limitar las consecuencias económicas de la pandemia y ayudar a impulsar la economía. Además, esta información debe ser ágil y constante mientras exista incertidumbre sobre la duración de esta crisis sanitaria. "Estamos ante un momento en el que se deben tomar decisiones rápidamente; lo que se decida tendrá importantes consecuencias" (Amador et al., 2020, p.1).

Este libro se centra en valorar el impacto económico que tendrá la crisis generada por la Covid-19 en la MIPYME de México. Se aporta información sobre las expectativas de crecimiento de empleo y ventas, y de diferentes indicadores de la organización de la empresa. Este informe pretende ser de utilidad a las empresas y a los distintos agentes económicos y sociales, facilitando información para la toma de decisiones principalmente en el ámbito económico y estratégico. Esta información será una valiosa herramienta para la planificación de las estrategias a seguir, tanto para la gestión de la empresa como de cara al establecimiento de políticas públicas que puedan dirigir convenientemente sus programas de actuación. Esto puede ayudar a impulsar la economía y propiciar una gestión eficiente de la crisis. 
Los objetivos específicos del informe son:

- Estimar el impacto de la crisis económica generada por la COVID-19 en el empleo, las ventas y en diferentes indicadores económicos y financieros para conocer las principales dificultades que atraviesan las empresas.

- Determinar el impacto de la crisis económica generada por la COVID-19 en la organización de la empresa.

- Estudiar de forma más profunda la actividad innovadora de la MIPYME y su acceso al financiamiento.

Para llevar a cabo este trabajo se ha realizado un estudio empírico a partir de la información proveniente de la encuesta realizada a 1416 MIPYMES mexicanas, dirigida al propietario o gerente/administrador de la empresa. La muestra está compuesta por microempresas (6 a 9 trabajadores), pequeña empresa (10 a 49) y medianas empresas (50 a 249). La técnica de recopilación de información fue una encuesta telefónica y online. El trabajo de campo se realizó durante los meses de febrero a abril de 2021. Hay que señalar que en el desarrollo de las distintas fases de esta investigación se ha respetado el secreto estadístico de la información facilitada por los participantes en el estudio.

Adicionalmente, cabe señalar, por un lado, que no es objetivo de este informe juzgar la situación de la MIPYME, sino más bien la de ofrecer una visión integral de estas empresas, que ponga de manifiesto, virtudes o desequilibrios, con el propósito de que sirva de referencia para que, en su caso, puedan adoptarse las medidas oportunas para potenciar las virtudes y ajustar los desequilibrios. 


\section{Metodología de investigación}

El diseño de la muestra y del cuestionario han sido realizados con las suficientes garantías que aseguran obtener una información estadísticamente válida para extraer conclusiones sobre los diversos aspectos que aborda este trabajo. En esta sección se expone la metodología del trabajo empírico realizado: estructura de la muestra, proceso de selección de las variables del cuestionario y técnicas estadísticas utilizadas en el proceso de resumen y análisis de la información obtenida.

\subsection{Estructura de la muestra}

El diseño general de la muestra se fundamenta en los principios del muestreo estratificado. Para ello, es necesario definir los criterios de estratificación que serán función de los objetivos del estudio, de la información disponible, de la estructura de la población y de los recursos disponibles para la realización del trabajo de campo. Los criterios utilizados para la estratificación deben estar correlacionados con las variables objeto de estudio, teniendo en cuenta que la ganancia en precisión es, en general, decreciente al aumentar el número de estratos. Por ello, el número de criterios y estratos debe ser moderado y congruente con el máximo tamaño de muestra con el que se pueda trabajar. En este trabajo se fijaron los siguientes estratos: sector (industria extractiva, construcción, comercio, manufactura, y servicios) y tamaños (micro, pequeñas y medianas empresas). Dentro de cada estrato, la selección se ha realizado mediante un muestreo aleatorio simple. El trabajo de campo se llevó a cabo a través de una encuesta telefónica y una plataforma online. 
Dado que el resultado final obtenido no es íntegramente proporcional a la población, fue necesaria la utilización de los correspondientes factores de elevación para la obtención de resultados agregados. Esto asegura un procedimiento objetivo y comparable para determinar la adecuación de la muestra a los objetivos de la investigación. No obstante, es importante resaltar que las distintas pruebas y contrastes estadísticos, que serán realizados en las fases posteriores del análisis, contarán con su nivel de significación o grado de precisión, determinado a partir de los datos realmente obtenidos en la encuesta y de acuerdo con las técnicas estadísticas utilizadas y al nivel de agregación establecido en cada caso.

Adicionalmente, se determina un nivel de confianza del 95\% para la muestra nacional y un error muestral de 2.6 puntos. Los tamaños poblacionales (número total de empresas en cada estrato) se obtuvieron del Directorio Estadístico Nacional de Unidades Económicas, editado por el Instituto Nacional de Estadística y Geografía (INEGI, 2020). La muestra obtenida fue de 1416 empresas mexicanas. En la Tabla 2.1 puede verse la distribución por sector y tamaño.

\section{Tabla 2.1}

Estructura de la muestra y error muestral

\section{Número de empresas en México}

Industria extractiva

Manufactura

378

Construcción

Comercio

236

Sector primario

Servicios

466

Otras actividades

179

Perdidos sistema 23

Microempresa (1 a 10 asalariados) 780

Pequeña (11 a 49 asalariados) 335

Mediana (50 a 249 asalariados) 285

Perdidos sistema 16

Total de la muestra 1416

Error muestral (nivel de confianza 95\%) 2.6 


\subsection{Selección de las variables y diseño del cuestionario}

La selección de las variables es fundamental en la configuración del análisis empírico, el cual permitirá afrontar adecuadamente el estudio del comportamiento de la empresa ante la crisis generada por la CoviD-19. Para obtener la información de las variables, se elaboró un cuestionario dirigido a los gerentes de las MIPYMEs. Con esta herramienta se ha buscado recoger de forma clara y concisa la información fundamental que constituye el objetivo de esta investigación. En su elaboración se ha prestado especial atención al orden y estructura de los bloques de preguntas, con la extensión más breve posible que permita una redacción clara y adecuada con el objetivo de reducir al máximo los posibles problemas de interpretación y obtención de datos en el proceso de cumplimentación del cuestionario.

Las técnicas de captación de información fueron la encuesta telefónica y electrónica, utilizando como soporte un cuestionario cerrado. Su diseño se efectuó a partir de la revisión de la literatura científica existente sobre los diversos aspectos investigados, así como del conocimiento previo de la realidad de las empresas, lo que sustenta y justifica que las variables incorporadas son relevantes para alcanzar los objetivos planteados.

En este sentido, el cuestionario se estructuró en dos bloques. En el primer bloque, se pregunta a los encuestados sobre los rasgos generales de sus empresas como el sector de actividad, la ubicación geográfica, el número de empleados, el género del gerente, el control familiar de la empresa, las expectativas de crecimiento de empleo y ventas, el grado de internacionalización y si han realizado teletrabajo.

En el segundo bloque, se recoge información sobre la forma como ha impactado la actual crisis generada por la COVID-19 en determinados indicadores de la empresa, la forma como ha afectado la crisis a la actividad de gestión de la empresa, el nivel de actividad desarrollada por la empresa, el acceso al financiamiento y sus indicadores de rendimiento. 


\subsection{Análisis estadístico de los datos}

Las variables de clasificación utilizadas para contrastar si existen diferencias significativas en el perfil de respuestas han sido: el tamaño, la antigüedad y el sector de actividad de la empresa. Para evaluar la significación estadística de las diferencias observadas en las respuestas, según el factor de clasificación utilizado, se han empleado las siguientes pruebas estadísticas:

- Cuando analizamos diferencias porcentuales se utiliza el análisis de tablas de contingencia aplicando la prueba de la $\mathrm{x}^{2}$ de Pearson con el fin de valorar si dos variables se encuentran relacionadas. Siempre que los datos lo permitan, se utilizan tablas $2 \times 2$, con lo que los resultados son más potentes, realizando en este caso la corrección por continuidad de Yates sobre la fórmula de la $\mathrm{x}^{2}$ de Pearson.

- En el caso de variables cuantitativas para las que se analice la diferencia de medias, según un criterio de clasificación, se ha utilizado el contraste de análisis de la varianza (ANOVA). 


\section{Datos generales de las empresas}

En esta sección se analizan las características generales más importantes de las empresas mexicanas que fueron encuestadas. Las empresas que configuran la muestra tienen las siguientes características:

- Respecto al tamaño, el $55.7 \%$ son micro, el $23.9 \%$ son pequeñas y $20.4 \%$ son medianas empresas.

- La antigüedad media de las empresas en México es de 12.7 años con una desviación estándar de 13.87 (Figura 3.1).

- Elcontroldelagestión delas empresas en México es, en su mayoría, de tipo familiar. El 70.2\% de las empresas están regidas en el entorno familiar (Figura 3.2).

- El 65.8\% de las MIPYMES mexicanas están gestionadas por hombres (Figura 3.3).

- Respecto a la formación del director/gerente, los datos muestran que el 68.6\% dispone de estudios universitarios (Figura 3.4). 
Figura 3.1

¿Cuántos años lleva funcionando su empresa?

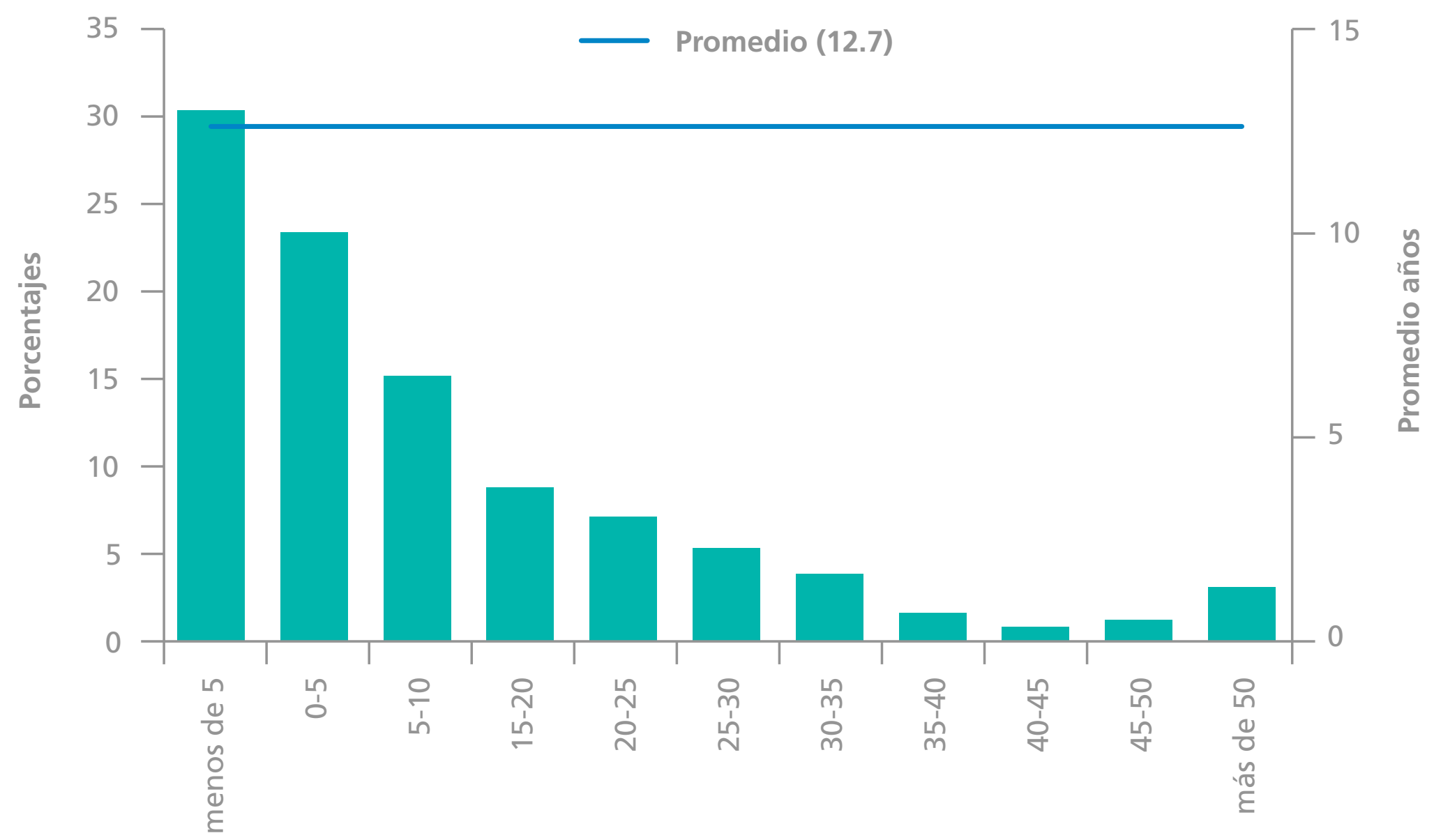

Figura 3.2

¿Considera que la empresa es una empresa familiar?

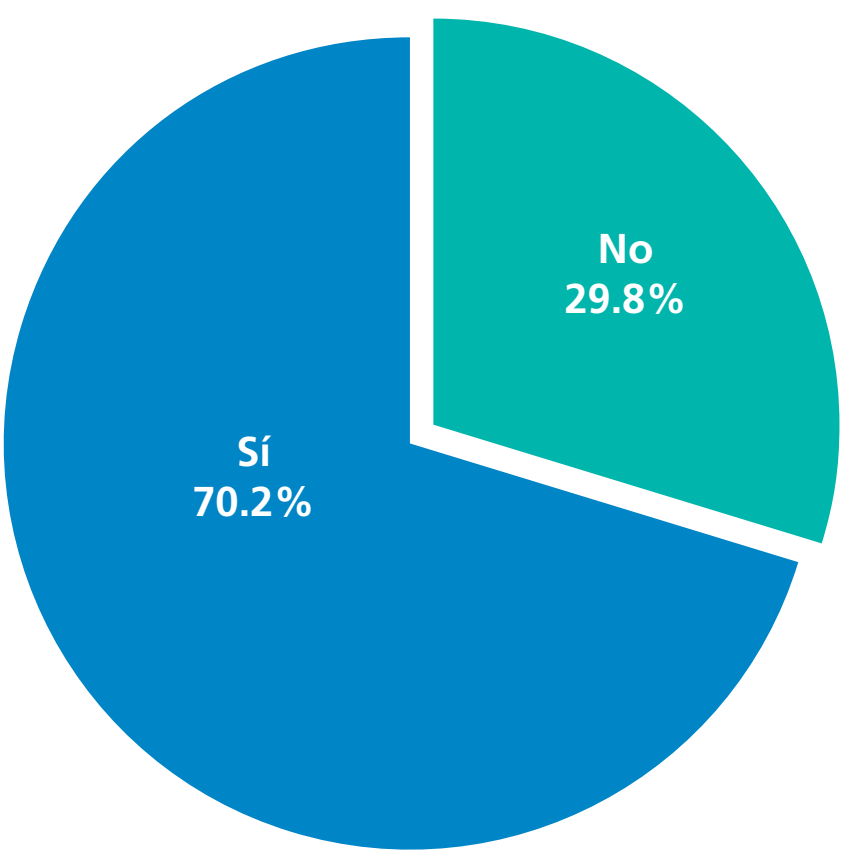


Figura 3.3

¿Cuál es el género del director general o gerente?

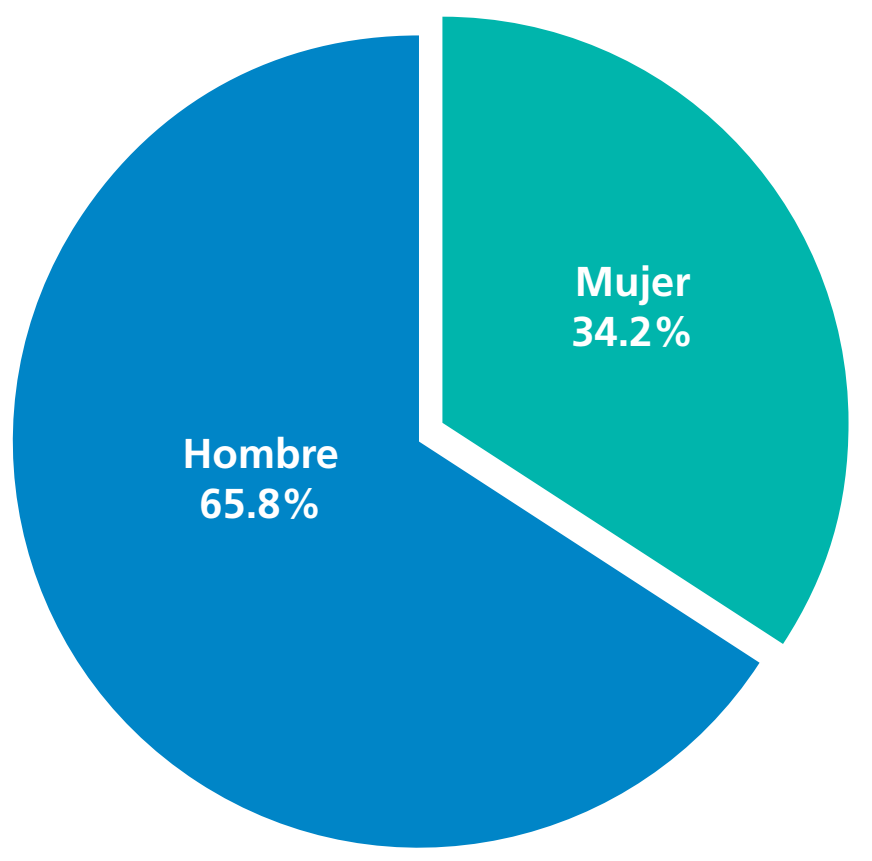

Figura 3.4

¿El director general o gerente dispone de estudios universitarios?

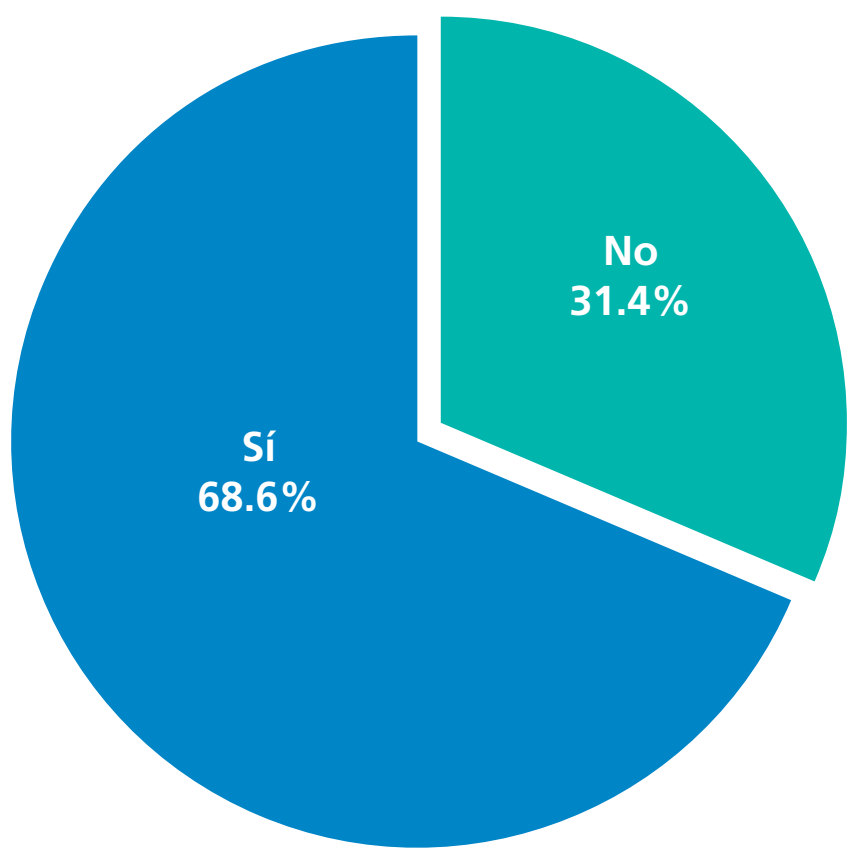

Como consecuencia de la contingencia por COVID-19, el 18.8\% de las MIPYMES utilizan el teletrabajo y solamente el $28.7 \%$ prevé que lo seguirá utilizando, aunque finalice la pandemia (Figura 3.5). El 22\% de las MIPYMES encuestadas obtuvieron algún tipo de apoyo debido a la Covid-19. 
Figura 3.5

Porcentaje de trabajadores que están en este momento realizando teletrabajo como consecuencia de la COVID-19 y previsión a utilizar en su organización el teletrabajo cuando finalice la pandemia

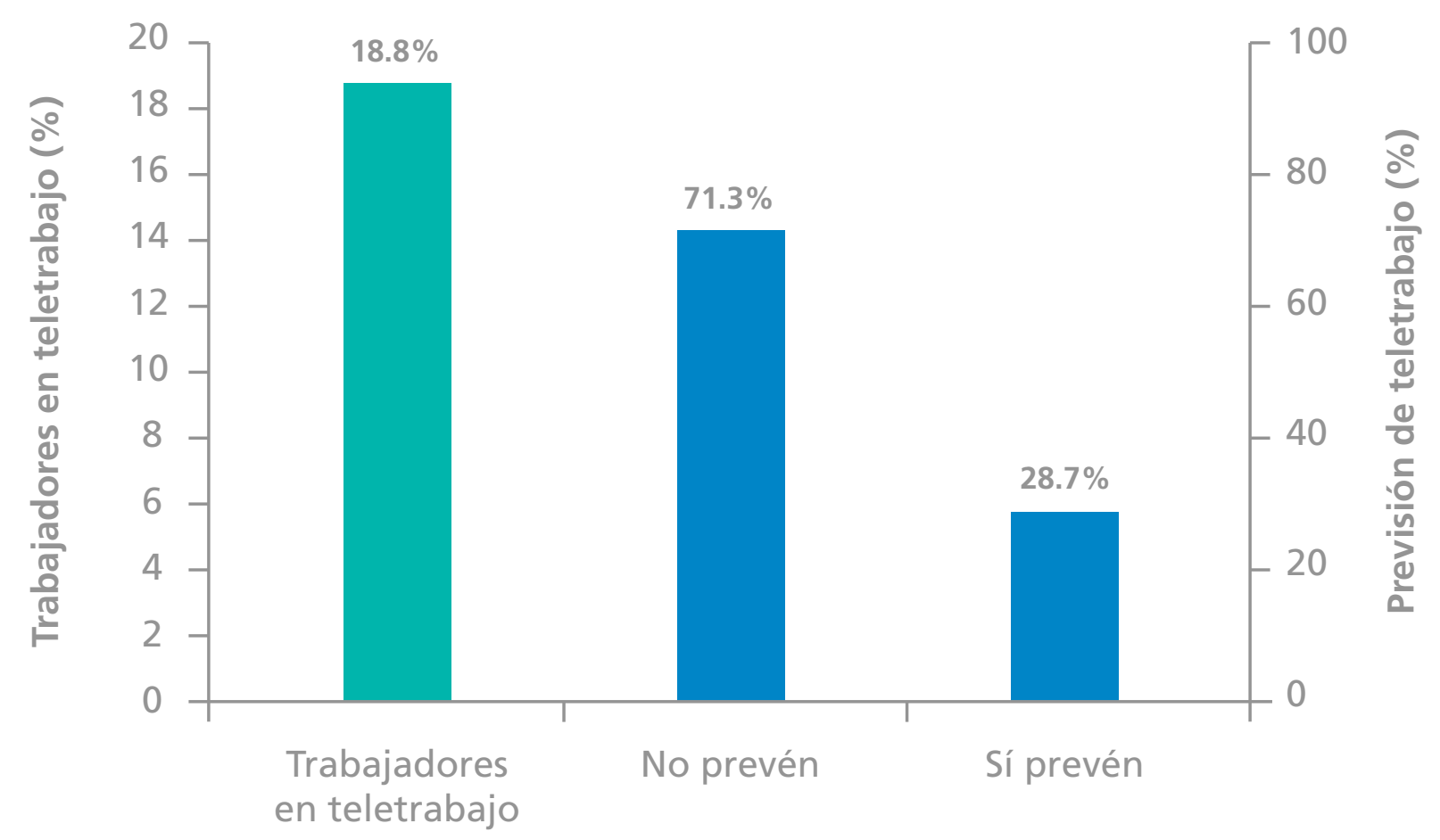




\section{Impacto económico}

La pandemia de COVID-19 ha generado una crisis económica en las empresas de México; muestra de esto es que el Producto Interno Bruto (PIB) registró una caída del 8.5\% en el año 2020, la caída más profunda desde la Gran Depresión, conocida también como crisis de 1929, que se prolongó hasta 1932, de acuerdo con cifras del INEGI (2021). En este apartado, se presenta la magnitud del impacto económico en México para la MIPYME, respecto al empleo, las ventas, los indicadores económico-financieros y la internacionalización.

\subsection{Empleo}

El promedio de empleados en las MIPYMES encuestadas es de 23 trabajadores para los años 2019 y 2020 (Figura 4.1). En lo que respecta a los niveles de empleo, en el año 2020, el 34.4\% de las empresas encuestadas experimentó una disminución del empleo; sin embargo, la expectativa para el 2021 es favorable, ya que solo el 7.8\% de las empresas prevé disminuir el número de empleados, aunado al $58.7 \%$ que espera mantener los niveles de empleo (Figuras 4.1 y 4.2). Al considerar la evolución del 2020, con relación al 2019, los sujetos de estudio se muestran más optimistas para el 2021; el 33.5\% cree que para el 2021 aumentará el número de empleados, el 58.7\% que mantendrá el mismo número y el 7.8\% que habrá una disminución. De tal forma que se puede observar que, en los años 2019 y 2020, hubo un 34.4\% de disminución en el empleo, rebasándolo con un 35.1\% que lo mantuvo y un 30.4\% de aumento (Figura 4.2). 
Figura 4.1

¿Cuántos han sido los empleados, en promedio, durante los años 2019 y 2020? ¿Cree que la tendencia para 2021 es aumentar, mantener o disminuir el número de empleados?

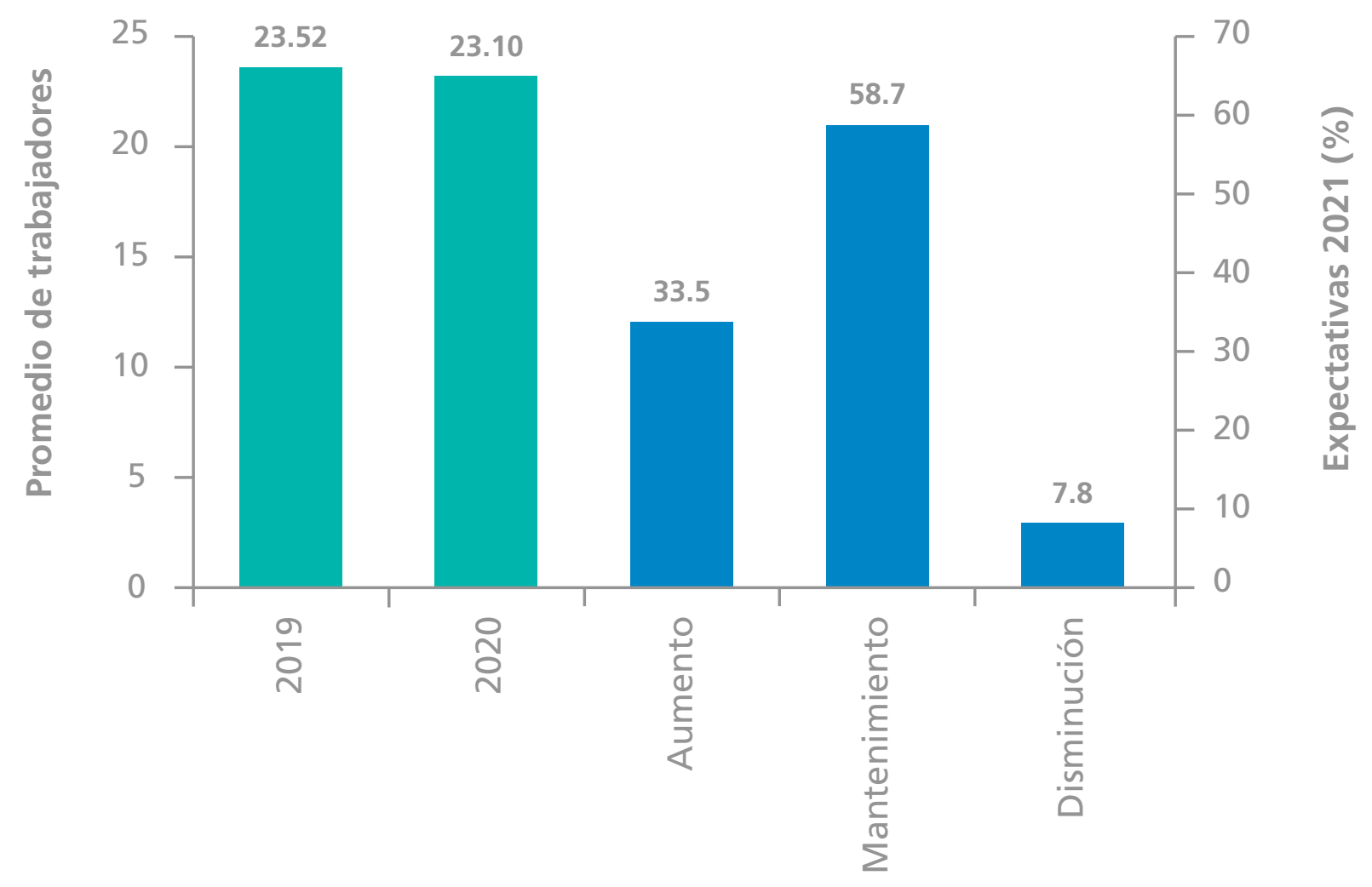

Figura 4.2

Evolución de los empleados durante los años 2019 y 2020 y previsión de la tendencia para 2021

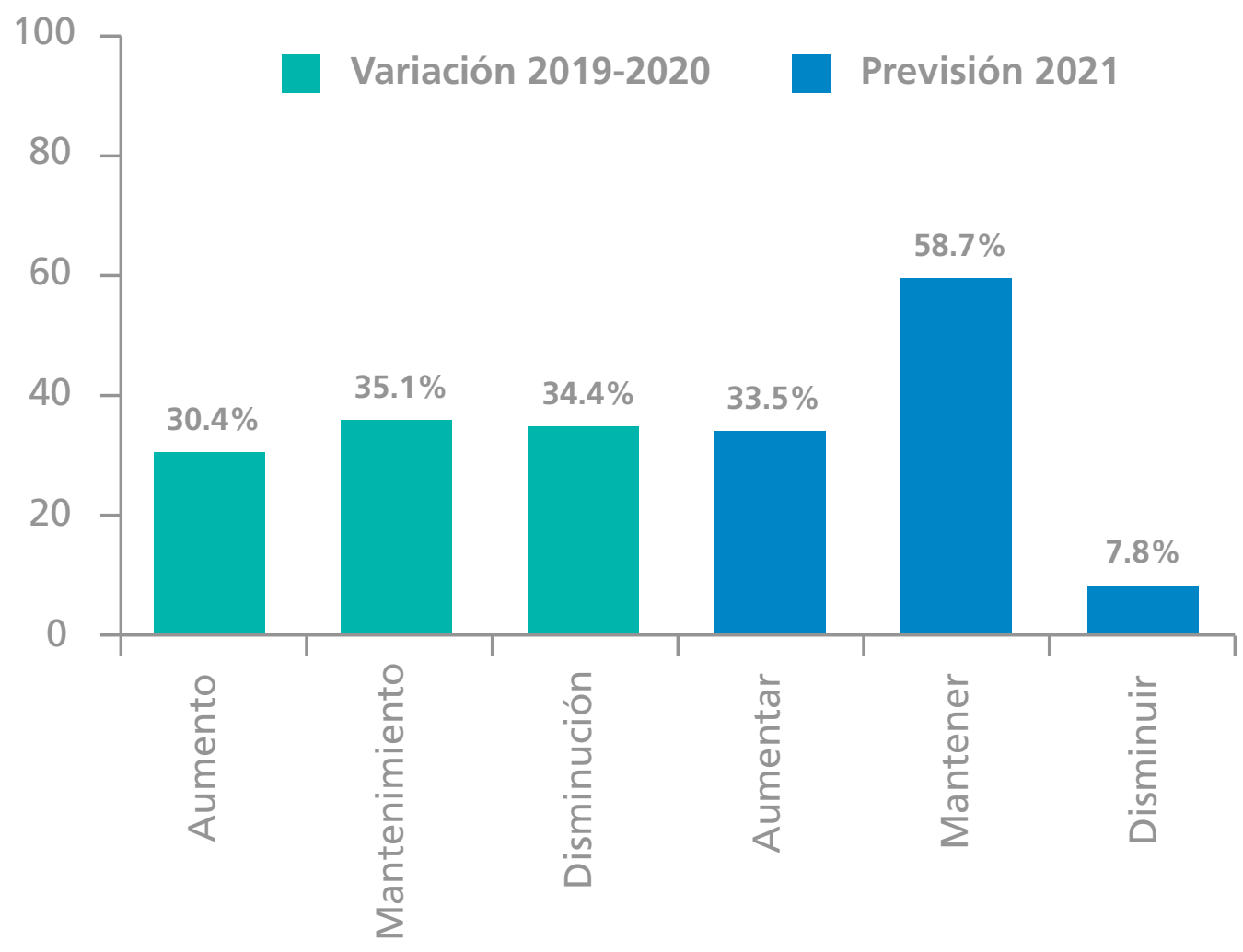


La Tabla 4.1 muestra el impacto en el empleo, de acuerdo con el tamaño de la empresa, aunque los resultados no fueron significativos desde el punto de vista estadístico. En cuanto al tamaño, se pudo observar que la evolución del empleo en el periodo 2019 y 2020 fue diferente, según el estrato considerado, arrojando un saldo negativo en todos los casos; en donde, las pequeñas empresas proyectaron un mayor saldo negativo de empleo (-5.9\%), seguida de las microempresas (-3.7\%) y las medianas de (-1.9\%). En cuanto a las expectativas del 2021 en generación de empleo, se observa una tendencia favorable, con un comportamiento muy similar en todos los casos; en donde predomina la estabilidad del empleo en las MIPYMEs, con una media superior al 55\% en todos los casos; destacándose las micro hasta en un $60.2 \%$. Asimismo, sin importar el tamaño, todas las empresas mostraron saldos positivos en cuanto a sus expectativas para el 2021; la muestra se comportó como sigue: las micro (25.3\%), las pequeñas (28.7\%) y las medianas (23.3\%).

\section{Tabla 4.1}

Impacto de la crisis sobre el empleo según el tamaño de la empresa

\begin{tabular}{|c|c|c|c|c|}
\hline & Micro & Pequeñas & Medianas & Sig. \\
\hline \multicolumn{5}{|l|}{$\begin{array}{l}\text { Evolución de los empleados } \\
\text { durante los años } 2019 \text { y } 2020\end{array}$} \\
\hline Aumento de empleo (\% empresas) & 28.4 & 34.6 & 31.6 & \\
\hline Estabilidad de empleo (\% empresas) & 39.4 & 25.0 & 34.9 & - \\
\hline Disminución de empleo (\% empresas) & 32.1 & 40.4 & 33.5 & \\
\hline Saldo de expectativas & -3.7 & -5.9 & -1.9 & \\
\hline \multicolumn{5}{|c|}{ Tendencia empleo 2021 (\% de empresas) } \\
\hline Aumento $(\%)$ & 32.6 & 35.9 & 33.8 & \\
\hline Estabilidad (\%) & 60.2 & 56.9 & 55.7 & - \\
\hline Disminución (\%) & 7.2 & 7.2 & 10.5 & \\
\hline Saldo de expectativas & 25.3 & 28.7 & 23.3 & \\
\hline
\end{tabular}

Nota. En una escala de $1=$ Total desacuerdo a $5=$ Total acuerdo. Diferencias estadísticamente significativas: $(*): p<0.1 ;(* *): p<0.05 ;(* * *): p<0.01$. - no significativa. 
En la Tabla 4.2 se analiza la evolución del empleo en el periodo de la crisis sanitaria. Del 2019 al 2020, un 30.4\% de las MIPYMES encuestadas presentaron un porcentaje en aumento de empleo, mientras que el 35.1\% manifestaron estabilidad y el 34.4\% tuvo una disminución de empleados. Respecto a las expectativas, se 1legó a la conclusión de un saldo negativo de -4.0\%, lo que quiere decir que en 2020 el empleo empeoró. Por otro lado, las expectativas de empleo para el 2021 presentó un saldo positivo del $25.7 \%$, esperando que el $58.7 \%$ de las empresas esté estable en el empleo.

\section{Tabla 4.2}

Impacto de la crisis sobre el empleo

$\%$

30.4

Aumento de empleo (\% empresas)

Estabilidad de empleo (\% empresas)

Disminución de empleo (\% empresas)

Saldo de expectativas

Tendencia empleo 2021 ( $\%$ de empresas)

Aumento (\%)

Estabilidad (\%)

Disminución (\%)

Saldo de expectativas

Nota. N.A. = No aplica

Para un análisis más detallado sobre la crisis de empleo, se analizó la evolución del empleo del 2019 al 2020, considerando la antigüedad de las empresas (Tabla 4.3). Las MIPYMES maduras mostraron las principales afectaciones en el empleo respecto a las jóvenes, presentando un porcentaje más bajo que las pequeñas en lo que respecta al aumento de empleo (21.5\%) y un porcentaje mayor en lo que respecta a la disminución de empleos (38.6\%). El saldo de las expectativas es de -17.1\% en las maduras, mientras que en las empresas jóvenes (menos de 10 años), el saldo de expectativas fue de $4.8 \%$. Por otro lado, en los saldos de expectativas para el 2021, las empresas maduras arrojaron un saldo de $11.4 \%$ y las jóvenes un $20.8 \%$, registrando un mayor porcentaje en la estabilidad (54.8\%), tal como se presenta en el Tabla 4.3. 


\section{Tabla 4.3}

Impacto de la crisis sobre el empleo, según la antigüedad de la empresa

\begin{tabular}{lccc} 
& $\begin{array}{c}\text { Jóvenes } \\
(\leq 10 \text { años })\end{array}$ & $\begin{array}{c}\text { Maduras } \\
(>10 \text { años })\end{array}$ & Sig. \\
\hline $\begin{array}{l}\text { Evolución de los empleados } \\
\text { durante los años } 2019 \text { y } 2020\end{array}$ & 36.3 & 21.5 \\
Aumento de empleo (\% empresas) & 32.2 & 39.8 & *** \\
Estabilidad de empleo (\% empresas) & 31.5 & 38.6 \\
Disminución de empleo (\% empresas) & 4.8 & -17.1 \\
\hline Saldo de expectativas & 37.8 & 26.8 \\
\hline Tendencia empleo 2021 (\% de empresas) & 54.8 & 65.0 \\
Aumento (\%) & 7.4 & 8.2 \\
Estabilidad (\%) & 20.8 & 11.4 \\
Disminución (\%) & & \\
\hline Saldo de expectativas & $3 *$ \\
\hline
\end{tabular}

Nota. Diferencias estadísticamente significativas: $\left(^{*}\right): p<0.1 ;(* *): p<0.05 ;(* *): p<0.01 ;(-)$ no significativa.

En lo concerniente al impacto generado por la crisis sobre los empleos, se analizó por sector de actividad de las empresas, observándose saldos negativos en todos los casos durante los años del 2019 y 2020 (Tabla 4.4); predominantemente, el sector que sufrió una mayor caída fue el de la construcción (-17.9\%), seguido del comercio (-14.4) y la industria (-6.2\%); cabe destacar que el sector que se vio menos afectado fue el de los servicios (-0.7). Los sectores que presentan una tendencia más favorable de empleo para 2021 son los sectores de la construcción (27.9\%), pese a que mostró una mayor caída en los periodos evaluados, seguido del servicio (26.8\%), la industria (24.10\%) y el comercio (22.2\%). 


\section{Tabla 4.4}

Impacto de la crisis sobre el empleo, según el sector de actividad de la empresa

\section{Industria Construcción Comercio Servicio Sig.}

Evolución de los empleados

durante los años 2019 y 2020

Aumento de empleo (\% empresas)

28.7

26.9

21.6

34.8

Estabilidad de empleo (\% empresas)

36.5

28.4

42.4

29.8

Disminución de empleo (\% empresas)

34.9

44.8

36.0

35.5

Saldo de expectativas

$-6.2$

$-17.9$

$-14.4$

$-0.7$

Tendencia empleo 2021

( $\%$ de empresas)

Aumento (\%)

32.0

41.2

29.9

34.6

Estabilidad (\%)

60.1

45.6

62.4

57.6

Disminución (\%)

7.9

13.2

7.7

7.8

Saldo de expectativas

24.1

27.9

22.2

26.8

Nota. Diferencias estadísticamente significativas: $\left(^{*}\right): p<0.1 ;(* *): p<0.05 ;(* *): p<0.01 ;(-)$ no significativa.

\subsection{Ventas}

En el año 2020, el nivel de ventas de las MIPYMES se vio afectado en el 51.9\% de ellas, con una reducción promedio del 23.8\% (Figuras 4.3 y 4.4). A pesar de este comportamiento negativo en 2020, las expectativas para el siguiente año fueron favorables, ya que el 52\% de las empresas encuestadas esperaban incrementar sus ventas en el primer semestre del 2021 y el 74.3\% tuvo la misma expectativa para el segundo semestre del mismo año (Figura 4.5) 
Figura 4.3

Comparando sus ventas en 2020 con relación a 2019 estas han...

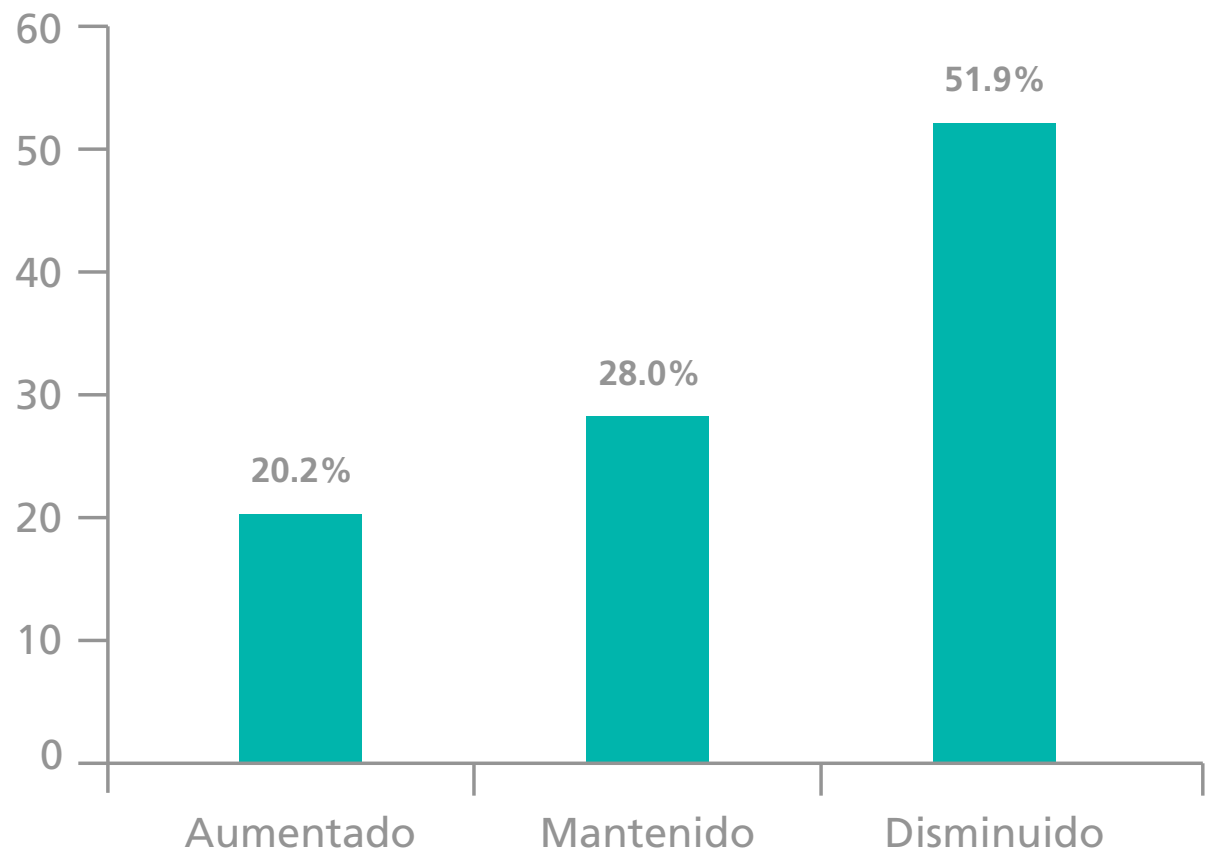

Figura 4.4

Porcentaje de variación de sus ventas en 2020 con relación a 2019

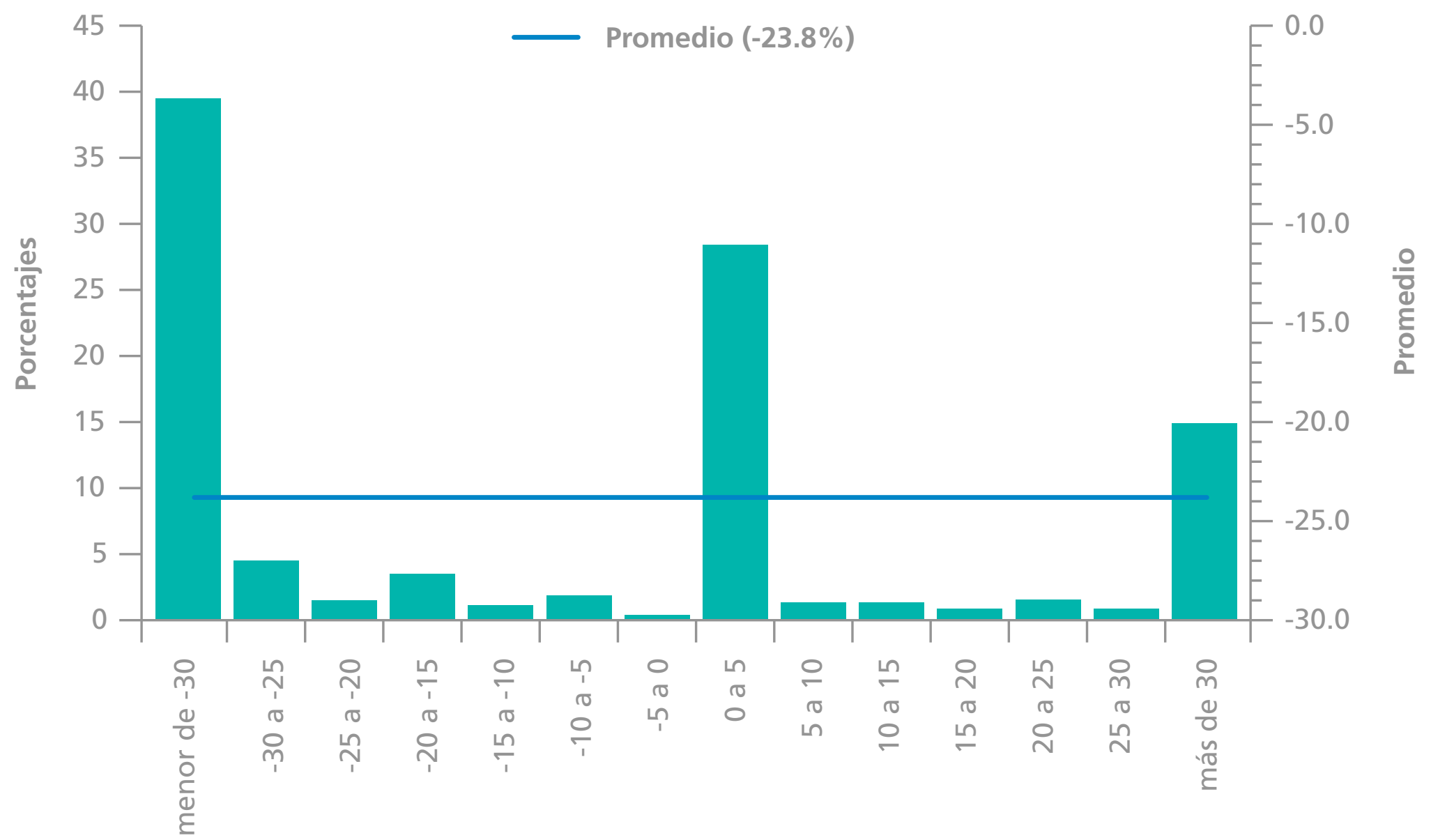


Figura 4.5

¿Cuáles son las expectativas de ventas de su empresa para el año 2021?

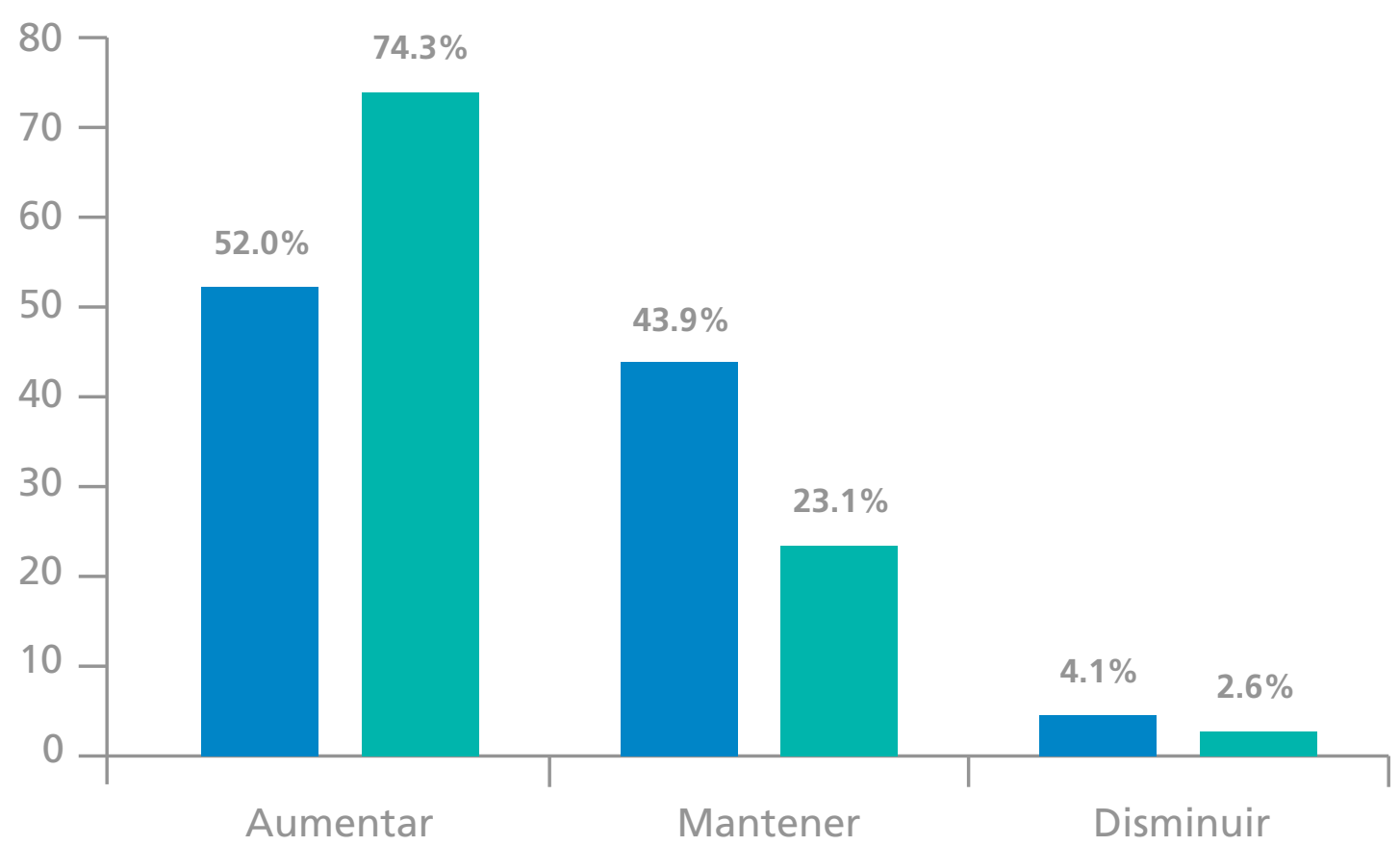

Primer semestre 2021

Segundo semestre 2021

Al analizar el comportamiento de las ventas por tamaño de empresa, se encontraron diferencias que son importantes resaltar, aunque estadísticamente no resultaron significativas (Tabla 4.5). El mayor impacto en la caída de las ventas en 2020 se ha experimentado en las pequeñas empresas, donde el 54.4\% redujeron sus ventas. Si se analiza el saldo de evolución de las ventas del 2020 (diferencia del porcentaje de empresas que aumentan menos las que disminuyen), las empresas medianas presentaron una evolución más favorable, aunque también con signo negativo, -23.7\%. Con respecto a las expectativas de ventas para el primer semestre de 2021, se logró ver una situación más favorable para las medianas empresas. Así, para el primer semestre, el saldo de expectativas fue de $47.1 \%$ para las microempresas, mientras que en las pequeñas fue de 48\% y las medianas de 51.2\%. Para el segundo semestre, la situación mejora sensiblemente en todos los estratos de tamaño analizados, presentando un saldo de expectativas positivo. 


\section{Tabla 4.5}

Impacto de la crisis sobre las ventas

\section{Tamaño de la empresa}

Micro

Pequeñas

Medianas

Sig.

Evolución de las ventas

entre 2019 y 2020

\begin{tabular}{|c|c|c|c|c|}
\hline Aumento (\%) & 19.4 & 20.4 & 22.7 & \\
\hline Mantenimiento (\%) & 28.4 & 25.2 & 30.8 & - \\
\hline Disminución (\% empresas) & 52.1 & 54.4 & 46.4 & \\
\hline Saldo de evolución & -32.7 & -33.9 & -23.7 & \\
\hline \multicolumn{5}{|l|}{$\begin{array}{l}\text { Expectativas de ventas } \\
\text { primer semestre } 2021\end{array}$} \\
\hline Aumento (\%) & 51.9 & 52.6 & 52.1 & \\
\hline Mantenimiento (\%) & 43.4 & 42.9 & 46.9 & - \\
\hline Disminución (\%) & 4.8 & 4.5 & .9 & \\
\hline Saldo de expectativas & 47.1 & 48.0 & 51.2 & \\
\hline \multicolumn{5}{|l|}{$\begin{array}{l}\text { Expectativas de ventas } \\
\text { segundo semestre } 2021\end{array}$} \\
\hline Aumento (\%) & 73.0 & 75.2 & 77.8 & \\
\hline Mantenimiento (\%) & 24.2 & 21.4 & 21.3 & - \\
\hline Disminución (\%) & 2.8 & 3.4 & 1.0 & \\
\hline Saldo de expectativas & 70.2 & 71.7 & 76.8 & \\
\hline
\end{tabular}

Nota. En una escala de $1=$ Total desacuerdo a $5=$ Total acuerdo. Diferencias estadísticamente significativas: $(*): p<0.1 ;(* *): p<0.05 ;(* * *): p<0.01 ;(-)$ no significativa.

Al analizar el comportamiento de las ventas por antigüedad de la empresa, se encontraron diferencias significativas en la evolución del 2019 al 2020. El mayor porcentaje de empresas que han visto disminuir sus ventas ha sido para las empresas jóvenes con un 48.5\%, mientras que las empresas maduras un 56.7\%; el saldo de la evolución es negativa tanto para las empresas jóvenes como para las maduras, sin embargo, la mayor afectación la tienen las empresas maduras con un saldo negativo de 39.7 (Tabla 4.6). La antigüedad ha ejercido una influencia estadísticamente significativa en las expectativas de ventas para el 2021. Las empresas jóvenes encuestadas consideran que tienen una alta expectativa para el primer y segundo semestre 
con relación a las empresas maduras; así, las empresas jóvenes tienen un saldo de expectativa de 51.9\% en el primer semestre, frente al 41.8\% de las empresas maduras; en el segundo semestre, las empresas jóvenes aumentan considerablemente al 72.7\%, quedando casi por igual a las empresas maduras con un $70.4 \%$.

\section{Tabla 4.6}

Impacto de la crisis sobre las ventas, según antigüedad de la empresa

Jóvenes
$(\leq 10$ años $)$$\quad \begin{gathered}\text { Maduras } \\ (>10 \text { años })\end{gathered} \quad$ Sig.

Evolución de las ventas entre 2019 y 2020

\begin{tabular}{|c|c|c|c|}
\hline Aumento (\%) & 22.5 & 17.0 & \\
\hline Mantenimiento (\%) & 29.0 & 26.3 & $* * *$ \\
\hline Disminución (\% empresas) & 48.5 & 56.7 & \\
\hline Saldo de evolución & -26.0 & -39.7 & \\
\hline \multicolumn{4}{|c|}{ Expectativas de ventas primer semestre 2021} \\
\hline Aumento (\%) & 55.3 & 47.2 & \\
\hline Mantenimiento (\%) & 41.3 & 47.4 & $* * *$ \\
\hline Disminución (\%) & 3.4 & 5.4 & \\
\hline Saldo de expectativas & 51.9 & 41.8 & \\
\hline \multicolumn{4}{|c|}{ Expectativas de ventas segundo semestre 2021} \\
\hline Aumento (\%) & 75.1 & 73.3 & \\
\hline Mantenimiento (\%) & 22.5 & 23.8 & - \\
\hline Disminución (\%) & 2.4 & 2.9 & \\
\hline Saldo de expectativas & 72.7 & 70.4 & \\
\hline
\end{tabular}

Nota. Diferencias estadísticamente significativas: $\left.{ }^{*}\right): p<0.1 ;\left({ }^{* *}\right): p<0.05 ;\left({ }^{* *}\right): p<0.01 ;(-)$ no significativa.

Al agrupar a las empresas encuestadas por sector de actividad, no se encontraron diferencias estadísticamente significativas en la evolución de las ventas entre 2019 y 2020, pero las expectativas de las ventas para el primer y segundo semestres del 2021 resultaron significativas (Tabla 4.7). Todos los sectores presentaron una evolución desfavorable en 2020, ya que más de la mitad de las empresas de todos 
los sectores experimentaron una disminución del 50\% de las ventas, pero fueron los sectores de la construcción (-42\%) y servicios (-34.8\%) los que reportaron las mayores disminuciones. Al igual que sucede con las expectativas de ventas para el primer semestre, aunque con un comportamiento más favorable e inclinado con resultados más favorables para el sector de servicios (50.1\%), las expectativas del segundo semestre son claramente positivas en los cuatro sectores, siguiendo con un registro de porcentaje elevado para el sector de servicios (74.5\%), a comparación del sector de construcción, que presenta un porcentaje más bajo que el resto de los sectores (40.9\%).

\section{Tabla 4.7}

Impacto de la crisis sobre las ventas, según sector de actividad de la empresa

\section{Industria Construcción Comercio Servicio Sig.}

Evolución de las ventas

entre 2019 y 2020

\begin{tabular}{llllll} 
Aumento (\%) & 20.5 & 13.0 & 21.7 & 19.3 \\
Mantenimiento (\%) & 28.1 & 31.9 & 26.4 & 26.6 & - \\
Disminución (\% empresas) & 51.4 & 55.1 & 51.9 & 54.1 \\
\hline Saldo de evolución & -31.0 & -42.0 & -30.2 & -34.8
\end{tabular}

Expectativas de ventas

primer semestre 2021

\begin{tabular}{|c|c|c|c|c|c|}
\hline Aumento (\%) & 49.9 & 47.8 & 52.1 & 52.8 & \\
\hline Mantenimiento (\%) & 44.6 & 40.6 & 44.5 & 44.5 & ** \\
\hline Disminución (\%) & 5.5 & 11.6 & 3.4 & 2.7 & \\
\hline Saldo de expectativas & 44.4 & 36.2 & 48.7 & 50.1 & \\
\hline \multicolumn{6}{|l|}{$\begin{array}{l}\text { Expectativas de ventas } \\
\text { segundo semestre } 2021\end{array}$} \\
\hline Aumento (\%) & 72.8 & 47.0 & 76.0 & 76.5 & \multirow{3}{*}{$* * *$} \\
\hline Mantenimiento (\%) & 24.5 & 47.0 & 20.5 & 21.4 & \\
\hline Disminución (\%) & 2.7 & 6.1 & 3.5 & 2.1 & \\
\hline Saldo de expectativas & 70.0 & 40.9 & 72.5 & 74.5 & \\
\hline
\end{tabular}

Nota. Diferencias estadísticamente significativas: $\left.{ }^{*}\right)$ : $\left.p<0.1 ;{ }^{* *}\right): p<0.05 ;(* * *): p<0.01 ;(-)$ no significativa. 


\subsection{Indicadores económicos y financieros}

En este apartado se analiza cómo la crisis provocada por Covid-19 afecta a los diferentes indicadores económicos y financieros de las MIPYMES mexicanas. En principio, se preguntó a los encuestados sobre los apoyos y beneficios que aprovecharon por parte del gobierno; al respecto, un $11.4 \%$ de los encuestados expresaron que han aprovechado los procesos de apoyo a las MIPYMEs, mientras que un 10.6\% aseguró haber aprovechado los subsidios o beneficios económicos estatales por COVID-19 (Figura 4.6).

\section{Figura 4.6}

¿Su empresa ha sido beneficiada?

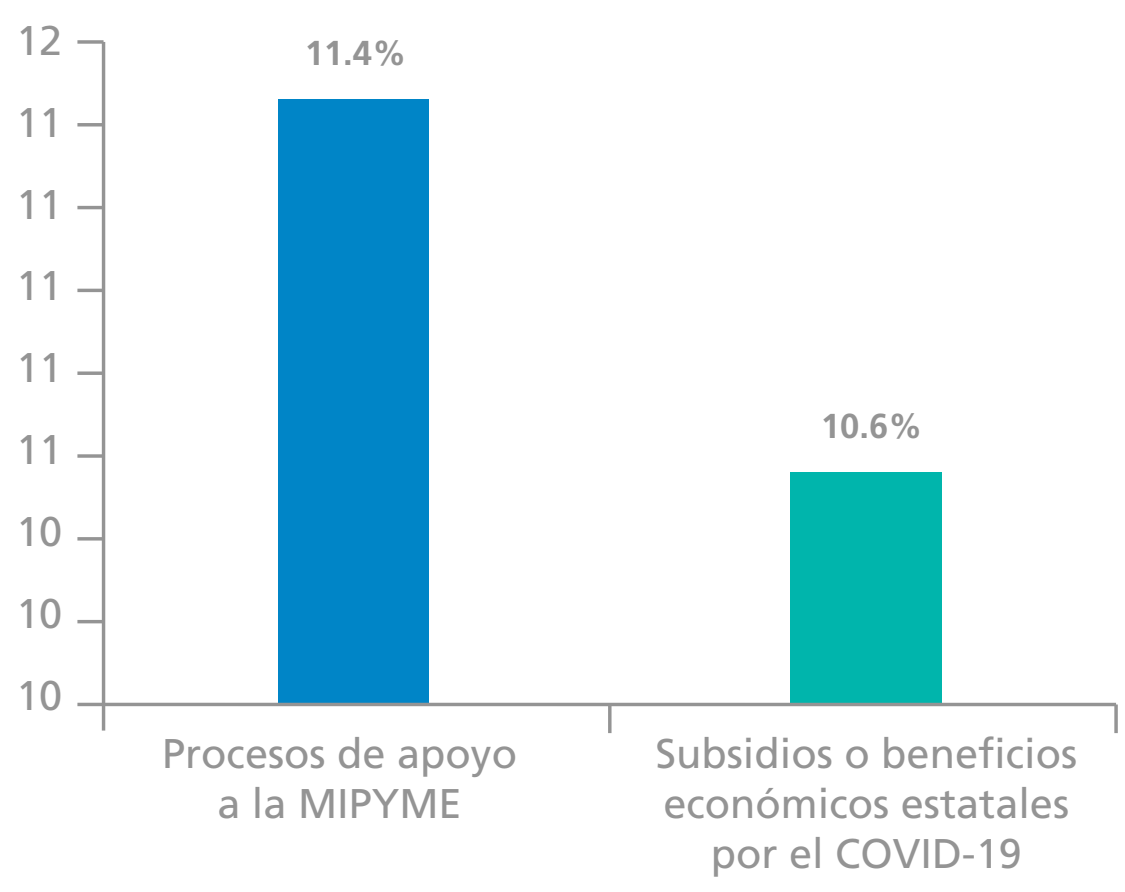

Al analizar cómo afectó en 2020 la crisis de COVID-19 a algunos indicadores económicos y financieros de las empresas encuestadas, se encontró que más de la mitad señalaron que fueron afectadas negativamente en todos los indicadores, siendo la productividad, la rentabilidad y el nivel de liquidez las más señaladas (Tabla 4.8). 


\section{Tabla 4.8}

Impacto de la crisis sobre indicadores económicos y financieros

\begin{tabular}{lcccc} 
& $\begin{array}{c}\text { No } \\
(\%)\end{array}$ & $\begin{array}{c}\text { Sí } \\
\text { Negativamente } \\
(\%)\end{array}$ & $\begin{array}{c}\text { Sí } \\
\text { Positivamente } \\
(\%)\end{array}$ & Sig. \\
\hline Facturación & 19.0 & 59.9 & 21.1 & N.A. \\
Rentabilidad & 14.6 & 61.8 & 23.6 & N.A. \\
Productividad & 11.3 & 62.8 & 26.0 & N.A. \\
Realización de inversiones & 21.5 & 58.9 & 19.7 & N.A. \\
Nivel de deuda & 27.4 & 55.7 & 16.9 & N.A. \\
Nivel de liquidez & 17.8 & 61.3 & 20.9 & N.A. \\
\hline
\end{tabular}

Nota. N.A. = No aplica.

La Figura 4.7 muestra el grado de impacto de la crisis sobre los indicadores económicos y financieros en 2020. Se presentan, en primera estancia, los niveles de facturación que tuvieron un impacto negativo en el 59.9\% de las empresas, con un grado de impacto de 2.94, en una escala del 1 al 5; mientras que un 21.1\% manifestaron un impacto positivo, con un grado de 2.78; y un 19.0\% manifestó que la crisis no tuvo impacto en su nivel de facturación.

El indicador de la rentabilidad se vio afectado negativamente en el 61.8\% de las empresas, con un grado de impacto de 2.99; el 23.6\% consideró que el impacto fue positivo, con un grado de 2.82; el 14.6\% manifestó que no tuvo impacto en este indicador.

Respecto a la productividad, el $62.8 \%$ de las empresas consideró tener un impacto negativo, con un grado de impacto de 2.99; el 26.0\% dijo tener un impacto positivo con un grado de 2.92; y el 11.3\% no manifestó efectos en este indicador.

El 58.9\% de las empresas indicó que la realización de inversiones se afectó negativamente con un grado de impacto de 3.06, siendo el mayor grado impacto negativo de todos los indicadores; el 19.7\% de las empresas tuvo un impacto positivo en este indicador con un grado de 2.74; y el 21.5\% no manifestó algún impacto.

Para el indicador de deuda, el 55.7\% de las empresas señaló un impacto negativo con un grado de 2.89; el 16.9\% indicaron que el impacto fue positivo con un grado de 2.48; y el 27.4\% manifestaron que no se afectó. 
Finalmente, en cuanto al nivel de liquidez, el 61.3\% de las empresas encuestadas manifestaron un impacto negativo con un grado de 2.88; el 20.9\% señalaron que el impacto fue positivo con un grado de 2.56; y el 17.8\% dijeron no haber experimentado algún efecto en este indicador.

\section{Figura 4.7}

Impacto de la crisis sobre indicadores económicos y financieros

IMPACTO COVID-19

Sobre indicadores...

Nivel de facturación

Rentabilidad

Productividad

La realización de inversiones

Nivel de deuda

Nivel de liquidez

\begin{tabular}{ccccc|}
$\begin{array}{c}\% \\
\text { No afectó }\end{array}$ & $\begin{array}{c}\% \\
\text { Negativo }\end{array}$ & $\begin{array}{c}\text { Grado de impacto } \\
\text { negativo }\end{array}$ & $\begin{array}{c}\% \\
\text { Positivo }\end{array}$ & $\begin{array}{c}\text { Grado de impacto } \\
\text { positivo }\end{array}$ \\
\hline
\end{tabular}

$19.0 \quad 59.9$

$14.6 \quad 61.8$

$11.3 \quad 62.8$

$21.5 \quad 58.9$

$27.4 \quad 55.7$

$17.8 \quad 61.3$
21.1

2.78

2.82

2.92

2.74

2.48

2.56

$\begin{array}{lllll}1 & 2 & 3 & 4 & 5\end{array}$

En la Tabla 4.9 se presentan los resultados referentes al impacto de la crisis sobre indicadores económicos y financieros agrupados por tamaño de la empresa. Aunque solo el indicador de facturación muestra una significancia estadística, en general, los resultados muestran que entre los diferentes grupos el comportamiento es similar; es decir, todos los grupos resultaron afectados negativamente en todos los indicadores. En cuanto a la facturación, las pequeñas empresas resultaron más afectadas negativamente (63.9\%), seguidas de las medianas (61.1\%) y, por último, las microempresas (57.8\%).

Al agrupar la información por antigüedad de la empresa, se obtuvieron diferencias significativas en el indicador de facturación y nivel de liquidez (Tabla 4.10). En el caso del indicador de facturación, el grupo de las empresas maduras resultaron ser las más afectadas negativamente, mientras que en el nivel de liquidez las jóvenes son la más afectadas. 
Tabla 4.9

Impacto de la crisis sobre indicadores económicos y financieros, según tamaño de la empresa

\begin{tabular}{|c|c|c|c|c|}
\hline & $\begin{array}{l}\text { No } \\
(\%)\end{array}$ & $\begin{array}{c}\text { Sí } \\
\text { Negativamente } \\
(\%)\end{array}$ & $\begin{array}{c}\text { Sí } \\
\text { Positivamente } \\
(\%)\end{array}$ & Sig \\
\hline \multicolumn{5}{|l|}{ Facturación } \\
\hline Microempresas & 22.1 & 57.8 & 20.1 & \multirow{3}{*}{ ** } \\
\hline Pequeñas & 14.5 & 63.9 & 21.7 & \\
\hline Medianas & 15.2 & 61.1 & 23.7 & \\
\hline \multicolumn{5}{|l|}{ Rentabilidad } \\
\hline Microempresas & 15.1 & 62.4 & 22.5 & \\
\hline Pequeñas & 12.0 & 62.5 & 25.5 & \multirow[t]{2}{*}{ - } \\
\hline Medianas & 16.7 & 58.9 & 24.4 & \\
\hline \multicolumn{5}{|l|}{ Productividad } \\
\hline Microempresas & 11.8 & 62.1 & 26.1 & \multirow{3}{*}{ - } \\
\hline Pequeñas & 11.0 & 64.9 & 24.1 & \\
\hline Medianas & 9.5 & 61.6 & 28.9 & \\
\hline \multicolumn{5}{|c|}{ Realización de inversiones } \\
\hline Microempresas & 22.1 & 57.9 & 20.0 & \multirow{3}{*}{ - } \\
\hline Pequeñas & 22.6 & 60.9 & 16.5 & \\
\hline Medianas & 17.6 & 58.6 & 23.8 & \\
\hline \multicolumn{5}{|l|}{ Nivel de deuda } \\
\hline Microempresas & 27.1 & 56.6 & 16.3 & \multirow{3}{*}{ - } \\
\hline Pequeñas & 28.9 & 52.3 & 18.8 & \\
\hline Medianas & 26.5 & 56.9 & 16.6 & \\
\hline \multicolumn{5}{|c|}{ Nivel de liquidez } \\
\hline Microempresas & 17.9 & 62.3 & 19.8 & \multirow{3}{*}{ - } \\
\hline Pequeñas & 17.0 & 60.2 & 22.8 & \\
\hline Medianas & 19.0 & 58.6 & 22.4 & \\
\hline
\end{tabular}

Nota. Diferencias estadísticamente significativas: $\left.{ }^{*}\right): p<0.1 ;(* *): p<0.05 ;(* *): p<0.01 ;(-)$ no significativa. 
Tabla 4.10

Impacto de la crisis sobre indicadores económicos y financieros, según antigüedad de la empresa

\begin{tabular}{|c|c|c|c|c|}
\hline & $\begin{array}{l}\text { No } \\
(\%)\end{array}$ & $\begin{array}{c}\text { Sí } \\
\text { Negativamente } \\
(\%)\end{array}$ & $\begin{array}{c}\text { Sí } \\
\text { Positivamente } \\
(\%)\end{array}$ & Sig. \\
\hline \multicolumn{5}{|c|}{ Facturación } \\
\hline Jóvenes & 20.3 & 57.2 & 22.5 & \\
\hline Maduras & 17.3 & 64.1 & 18.7 & ** \\
\hline \multicolumn{5}{|c|}{ Rentabilidad } \\
\hline Jóvenes & 13.6 & 62.0 & 24.5 & \\
\hline Maduras & 16.4 & 61.3 & 22.3 & - \\
\hline \multicolumn{5}{|c|}{ Productividad } \\
\hline Jóvenes & 10.5 & 62.8 & 26.7 & \\
\hline Maduras & 12.8 & 62.3 & 24.9 & - \\
\hline \multicolumn{5}{|c|}{ Realización de inversiones } \\
\hline Jóvenes & 20.8 & 58.9 & 20.3 & \\
\hline Maduras & 23.0 & 58.2 & 18.7 & - \\
\hline \multicolumn{5}{|c|}{ Nivel de deuda } \\
\hline Jóvenes & 28.9 & 54.3 & 16.8 & \\
\hline Maduras & 25.8 & 56.9 & 17.3 & - \\
\hline \multicolumn{5}{|c|}{ Nivel de liquidez } \\
\hline Jóvenes & 16.2 & 61.7 & 22.2 & \\
\hline Maduras & 20.8 & 59.9 & 19.3 & * \\
\hline
\end{tabular}

Nota. Diferencias estadísticamente significativas: $\left.{ }^{*}\right): p<0.1 ;(* *): p<0.05 ;(* * *): p<0.01 ;(-)$ no significativa. 
Tabla 4.11

Impacto de la crisis sobre indicadores económicos y financieros

\section{Sector de actividad de la empresa}

\begin{tabular}{|c|c|c|c|c|}
\hline & $\begin{array}{l}\text { No } \\
(\%)\end{array}$ & $\begin{array}{c}\text { Sí } \\
\text { Negativamente } \\
(\%)\end{array}$ & $\begin{array}{c}\text { Sí } \\
\text { Positivamente } \\
(\%)\end{array}$ & Sig. \\
\hline \multicolumn{5}{|l|}{ Facturación } \\
\hline Industria & 17.3 & 57.6 & 25.1 & \multirow{4}{*}{$\star * \star$} \\
\hline Construcción & 17.6 & 73.5 & 8.8 & \\
\hline Comercio & 23.7 & 59.7 & 16.5 & \\
\hline Servicios & 16.5 & 62.9 & 20.5 & \\
\hline \multicolumn{5}{|l|}{ Rentabilidad } \\
\hline Industria & 16.8 & 55.9 & 27.4 & \multirow{4}{*}{ ** } \\
\hline Construcción & 15.9 & 71.0 & 13.0 & \\
\hline Comercio & 16.2 & 63.2 & 20.5 & \\
\hline Servicios & 11.6 & 66.7 & 21.6 & \\
\hline \multicolumn{5}{|c|}{ Productividad } \\
\hline Industria & 9.5 & 60.7 & 29.8 & \multirow{4}{*}{$* * *$} \\
\hline Construcción & 10.1 & 79.7 & 10.1 & \\
\hline Comercio & 16.2 & 65.8 & 17.9 & \\
\hline Servicios & 9.5 & 63.3 & 27.1 & \\
\hline \multicolumn{5}{|c|}{ Realización de inversiones } \\
\hline Industria & 18.8 & 59.3 & 22.0 & \multirow{4}{*}{ * } \\
\hline Construcción & 26.1 & 63.8 & 10.1 & \\
\hline Comercio & 25.2 & 59.8 & 15.0 & \\
\hline Servicios & 18.7 & 60.5 & 20.8 & \\
\hline \multicolumn{5}{|c|}{ Nivel de deuda } \\
\hline Industria & 26.0 & 53.3 & 20.7 & \multirow{4}{*}{-} \\
\hline Construcción & 20.3 & 66.7 & 13.0 & \\
\hline Comercio & 31.3 & 53.2 & 15.5 & \\
\hline Servicios & 25.7 & 57.8 & 16.5 & \\
\hline \multicolumn{5}{|c|}{ Nivel de liquidez } \\
\hline Industria & 16.4 & 58.8 & 24.8 & \multirow{4}{*}{ ** } \\
\hline Construcción & 20.6 & 70.6 & 8.8 & \\
\hline Comercio & 21.0 & 62.2 & 16.7 & \\
\hline Servicios & 15.7 & 63.8 & 20.5 & \\
\hline
\end{tabular}

Nota. Diferencias estadísticamente significativas: $\left({ }^{*}\right): p<0.1 ;(* *): p<0.05 ;(* *): p<0.01 ;(-)$ no significativa.. 
La Tabla 4.11 muestra la información agrupada por sector de actividad, encontrándose diferencias estadísticamente significativas en casi todos los indicadores; solo el indicador nivel de deuda no tuvo significancia estadística. En general, todos los sectores se han visto afectados negativamente en todos los indicadores. Respecto a la facturación, el sector más afectado negativamente es el de la construcción (73.5\%), seguido por el de servicios (62.9\%), el comercio (59.7\%) y la industria (57.6\%). En cuanto a la rentabilidad, se sigue el mismo comportamiento: construcción (71.0\%), seguido por el de servicios (66.7\%), el comercio (63.2\%) y la industria (55.9\%). La productividad se afectó negativamente, principalmente en el sector construcción (79.7\%), seguido de comercio (65.8\%), de servicios (63.3\%) y de la industria (60.7\%). La realización de inversiones se vio afectada negativamente en el sector construcción (63.8\%), seguido por el de servicios (60.5\%), el de comercio (59.8\%) y el de industria (59.3\%). El nivel de liquidez se afectó negativamente en el sector construcción (70.6\%), seguido por el de servicios (63.8\%), el de comercio (62.2\%) y el de industria (58.8\%).

\subsection{Internacionalización}

La Figura 4.8 muestra que el 17.9\% de las empresas realizaron ventas internacionales en el año 2020, con un promedio total de ventas del 37.4\%.

La Figura 4.9 muestra el impacto de la crisis generada por la CoviD-19 sobre la internacionalización de las empresas. Los resultados muestran que el 53.4\% de las empresas internacionalizadas sufrieron un impacto negativo en su nivel de facturación a mercados internacionales, con un grado de impacto de 2.74. El impacto negativo también se refleja en el número de países destino; al respecto, el 43\% de las empresas fueron afectadas negativamente con un grado de 2.50. Cabe destacar que un porcentaje importante no manifestó afectación en el nivel de facturación a mercados internacionales (32\%) y en el número de países destino (43\%). 


\section{Figura 4.8}

Porcentaje de empresas exportadoras y porcentaje de ventas en 2020 destinado a mercados internacionales

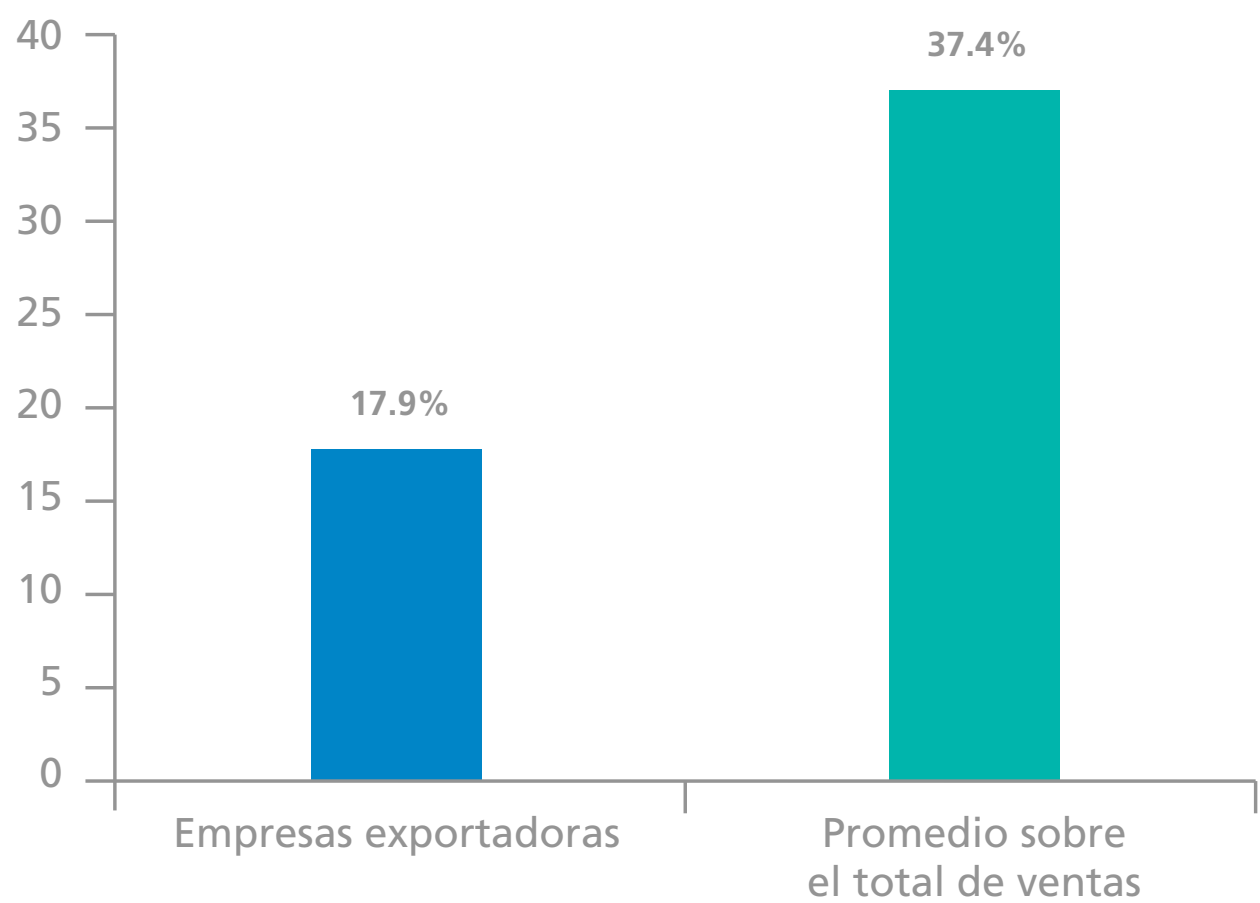

Figura 4.9

Impacto de la crisis en la internacionalización

IMPACTO COVID-19

Impacto sobre...

Nivel de facturación

a mercados internacionales

Número de países

de destino

\begin{tabular}{ccccc}
$\begin{array}{c}\% \\
\text { No afectó }\end{array}$ & $\begin{array}{c}\text { Negativo } \\
\text { Grado de impacto } \\
\text { negativo }\end{array}$ & $\begin{array}{c}\% \\
\text { Positivo }\end{array}$ & $\begin{array}{c}\text { Grado de impacto } \\
\text { positivo }\end{array}$ \\
\hline
\end{tabular}

32.0

53.4

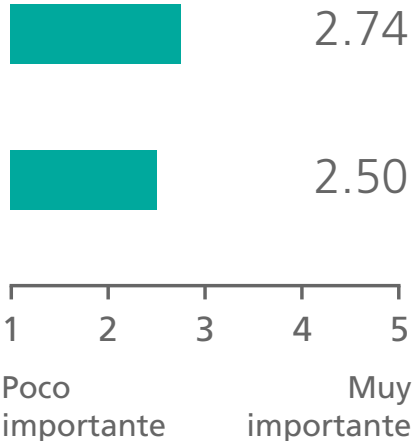

14.6

2.61

42.2

43.0

$2.50 \quad 14.8$

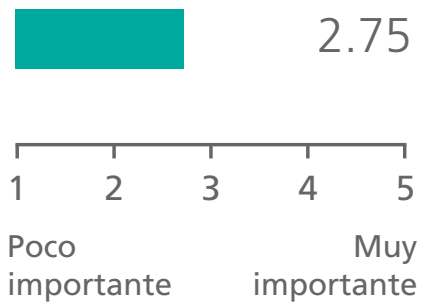




\section{Impacto sobre la organización de la empresa}

La crisis sanitaria no solo ha impactado en el crecimiento económico y en el empleo de las empresas, sino que también en la gestión de las actividades de las empresas. En este apartado, se preguntó a los encuestados sobre el impacto que habían sufrido diferentes actividades de gestión, a partir de una escala Likert de 5 puntos. Las actividades se han clasificado en: (1) actividades con clientes y proveedores, (2) actividades operativas y (3) actividades estratégicas.

\subsection{Actividades con clientes y proveedores}

El impacto más significativo de la crisis ocasionada por la CoviD-19 es que se han visto afectadas las empresas en su cadena de suministros, al sufrir retrasos por parte de sus proveedores (3.07 en una escala de 1 a 5) (Figura 5.1). El resto de las variables quedan por debajo del valor de 3 . Esto, en cierta medida, parece indicar que esta crisis no ha afectado, al menos todavía, a la gestión de sus operaciones con sus clientes y proveedores. Así, los encuestados otorgaron valores de 2.72 a que las condiciones de pago de los clientes se han vuelto más largas, 2.66 a la cancelación de pedidos por parte de los clientes ha aumentado significativamente, 2.82 a que los proveedores han endurecido sus condiciones de pago y 2.47 a que las pérdidas por impago de clientes han aumentado.

Para un mayor detalle, a continuación, veremos el comportamiento de este tipo de actividades en función de una serie de factores. En el tamaño de la empresa encontramos que existe una diferencia significativa en las pequeñas empresas (3.20), se ha visto afectada la cadena de proveedores no existiendo diferencias 
estadísticamente significativas en los otros cuatro aspectos (Tabla 5.1). Por lo que el factor tamaño no parece que haya sido relevante en las actividades analizadas relacionadas con los clientes y proveedores.

Figura 5.1

Actividades con clientes y proveedores

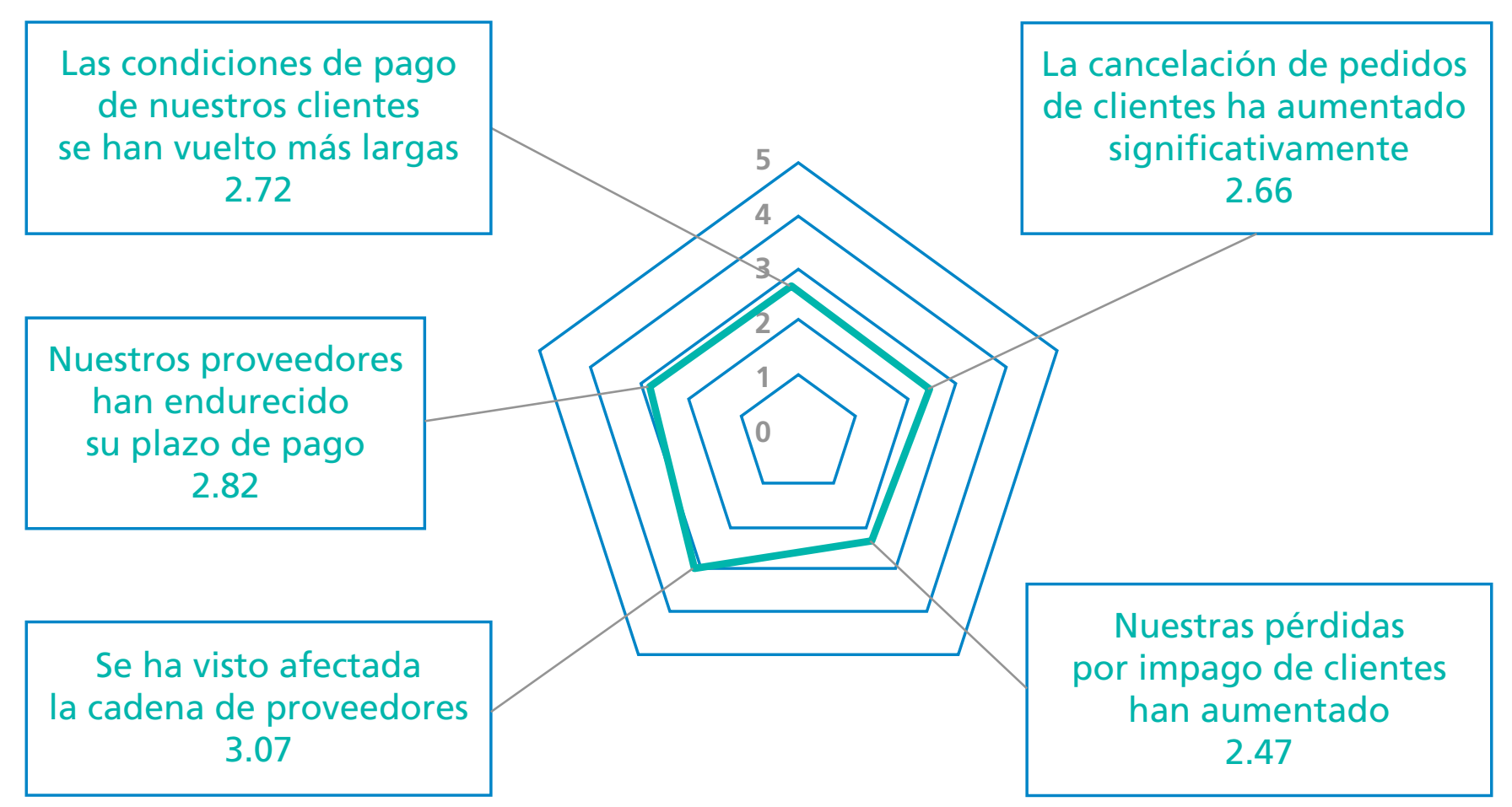

Nota. 1 = Total desacuerdo; 5 = Total acuerdo.

\section{Tabla 5.1}

Actividades con clientes y proveedores, según tamaño de la empresa

\section{Micro Pequeñas Medianas Sig.}

Se ha visto afectada la cadena de proveedores

$\begin{array}{llll}3.06 & 3.20 & 2.88\end{array}$ *

Nuestros proveedores han endurecido su plazo de pago

$2.79 \quad 2.90 \quad 2.82$

Las condiciones de pago de nuestros clientes se han vuelto más largas

$\begin{array}{lll}2.70 & 2.75 & 2.74\end{array}$

La cancelación de pedidos de clientes

ha aumentado significativamente

$\begin{array}{lll}2.68 & 2.65 & 2.58\end{array}$

Nuestras pérdidas por impago de clientes han aumentado

$\begin{array}{lll}2.43 & 2.60 \quad 2.38\end{array}$

Nota. En una escala de $1=$ Total desacuerdo a $5=$ Total acuerdo.

Diferencias estadísticamente significativas: $\left(^{*}\right): p<0.1 ;(* *): p<0.05 ;(* * *): p<0.01$. (-) no significativa. 
En cuanto a la edad de la empresa surgen algunas diferencias estadísticamente significativas (Tabla 5.2). La más relevante es que las empresas maduras se han visto más afectadas con relación a que los proveedores han endurecido sus plazos de pago (2.95) que las empresas jóvenes (2.74). Del mismo modo, las empresas maduras han tenido un mayor impacto negativo en las condiciones de pago de sus clientes, ya que se volvieron más largas (2.84 vs 2.64). En cuanto al sector, se puede destacar que las empresas de la construcción han sido las más afectadas en las actividades con clientes y proveedores (Tabla 5.3). Así, han experimentado una mayor cancelación de pedidos de sus clientes (3.13), más impagos de clientes (2.99), los clientes han alargado más sus pagos (3.58), se ha visto afectada su cadena de proveedores (3.39) y estos han endurecido sus plazos de pago (3.38) que en el resto de los sectores.

\section{Tabla 5.2}

Actividades con clientes y proveedores, según antigüedad de la empresa

\begin{tabular}{lccc} 
& $\begin{array}{c}\text { Jóvenes } \\
(\leq 10 \text { años })\end{array}$ & $\begin{array}{c}\text { Maduras } \\
(>10 \text { años })\end{array}$ & Sig. \\
$\begin{array}{l}\text { Se ha visto afectada la cadena } \\
\text { de proveedores }\end{array}$ & 3.04 & 3.13 & $* *$ \\
$\begin{array}{l}\text { Nuestros proveedores han endurecido } \\
\text { su plazo de pago }\end{array}$ & 2.74 & 2.95 & $* *$ \\
$\begin{array}{l}\text { Las condiciones de pago de nuestros clientes } \\
\text { se han vuelto más largas } \\
\begin{array}{l}\text { La cancelación de pedidos de clientes } \\
\text { ha aumentado significativamente }\end{array}\end{array}$ & 2.64 & 2.84 & - \\
$\begin{array}{l}\text { Nuestras pérdidas por impago de clientes } \\
\text { han aumentado }\end{array}$ & 2.66 & 2.65 & - \\
\hline
\end{tabular}

Nota. Diferencias estadísticamente significativas: $(*): p<0.1 ;(* *): p<0.05 ;(* * *): p<0.01 ;(-)$ no significativa. 
Tabla 5.3

Actividades con clientes y proveedores, según sector de actividad de la empresa

Industria Construcción Comercio Servicio Sig.

Se ha visto afectada

la cadena de proveedores

$\begin{array}{llll}3.09 & 3.39 & 3.30 & 3.01\end{array}$ **

Nuestros proveedores

han endurecido su plazo de pago

2.93

3.38

2.84

2.76

Las condiciones de pago

de nuestros clientes

2.80

3.58

2.55

2.69

$\star \star \star$

se han vuelto más largas

La cancelación de pedidos

de clientes ha aumentado

2.70

3.13

2.40

2.77

significativamente

Nuestras pérdidas por impago

de clientes han aumentado

2.57

2.99

2.25

2.49

$\star \star \star$

Nota. Diferencias estadísticamente significativas: $\left(^{*}\right): p<0.1 ;(* *): p<0.05 ;(* * *): p<0.01 ;(-)$ no significativa.

\subsection{Actividades operativas}

En las actividades operativas de las empresas analizadas, se aprecia un menor impacto. Todas las valoraciones tienen valores en 3 (3.08 y 3.3) en una escala de 1 a 5 (Figura 5.2). Las actividades más afectadas han sido que las empresas han tenido que realizar cambios específicos a nivel operativo para adaptarse a la situación de la crisis (3.08) y que han tenido que modificar su oferta de productos o servicios para abordar nuevos clientes (3.3). Mientras que actividades como bajar precios (2.67) o necesitar aumentar la subcontratación de sus operaciones (2.17) han tenido un impacto muy bajo.

La Tabla 5.4 muestra cómo han afectado las actividades operativas a las empresas según su tamaño. Y se puede apreciar que las empresas pequeñas han sido las que más han recurrido a la subcontratación de sus operaciones (2.28), asimismo, han tenido que bajar sus precios (2.73). Respecto al factor antigüedad de la empresa (Tabla 5.5), las empresas más jóvenes se han visto más afectadas al tener que bajar sus precios (2.73).

Por último, en el factor sector (Tabla 5.6), se observa que las empresas del sector industrial son las que han tenido que realizar más cambios operativos (3.22), 
también, las que han aumentado la subcontratación de sus operaciones (2.43); las empresas de servicios han modificado más su oferta de productos/servicios para abordar nuevos clientes (3.43).

Figura 5.2

Actividades operativas

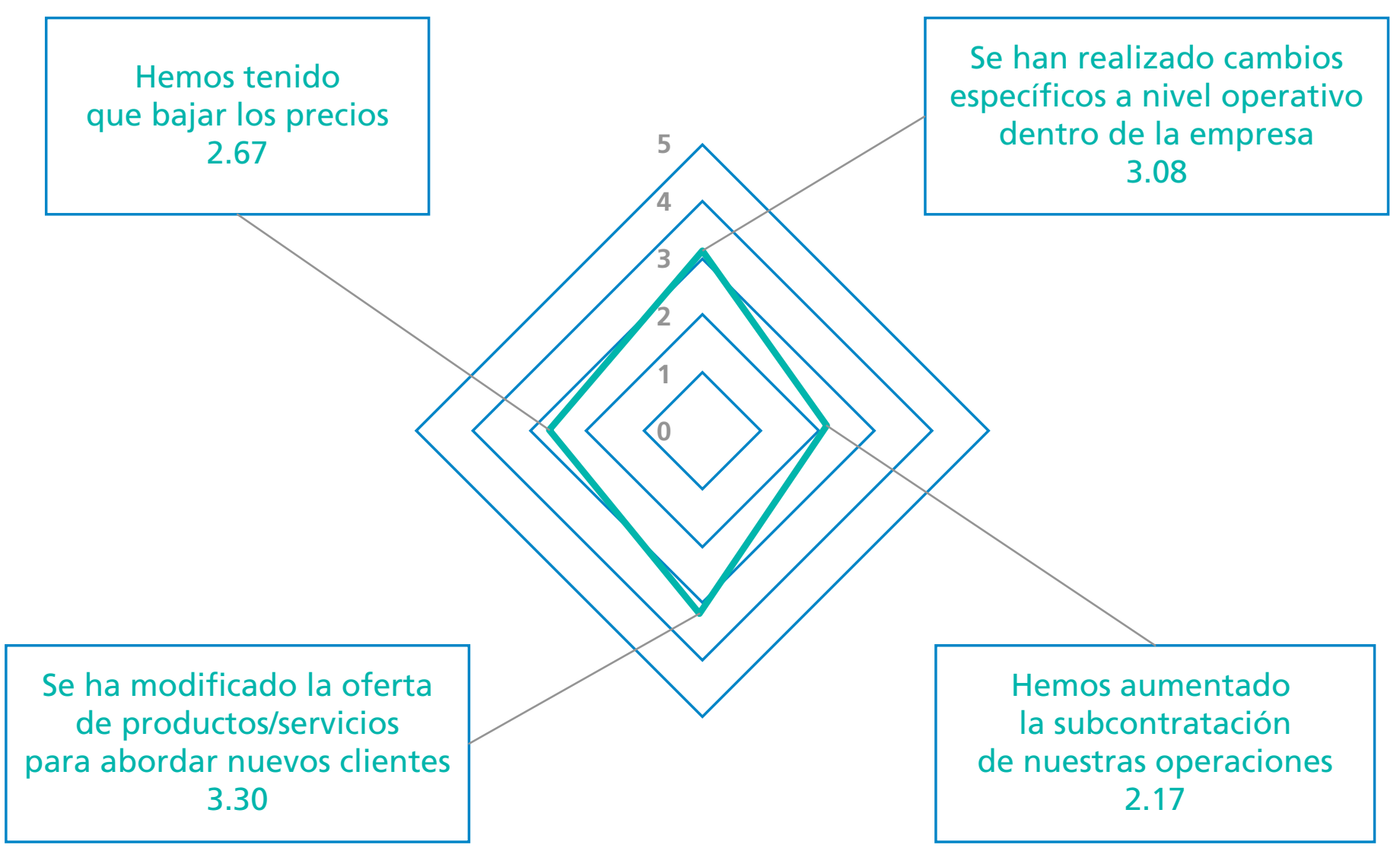

Nota. 1 = Total desacuerdo; 5 = Total acuerdo.

\section{Tabla 5.4}

Actividades operativas, según tamaño de la empresa

\section{Micro Pequeñas Medianas Sig.}

Se han realizado cambios específicos a nivel operativo dentro de la empresa

$\begin{array}{lll}3.05 & 3.09 & 3.15\end{array}$

Hemos aumentado la subcontratación de nuestras operaciones

$\begin{array}{lll}2.10 & 2.28 & 2.27\end{array}$ **

Se ha modificado la oferta de productos/servicios para abordar nuevos clientes

$\begin{array}{lll}3.28 & 3.31 \quad 3.35\end{array}$

Hemos tenido que bajar los precios

2.70

2.73

2.44

$\star \star$

Nota. En una escala de $1=$ Total desacuerdo a $5=$ Total acuerdo.

Diferencias estadísticamente significativas: $\left(^{*}\right): p<0.1 ;(* *): p<0.05 ;(* * *): p<0.01 ;(-)$ no significativa. 
Tabla 5.5

Actividades operativas, según antigüedad de la empresa

\begin{tabular}{lccc} 
& $\begin{array}{c}\text { Jóvenes } \\
(\leq 10 \text { años })\end{array}$ & $\begin{array}{c}\text { Maduras } \\
(>10 \text { años })\end{array}$ & Sig. \\
$\begin{array}{l}\text { Se han realizado cambios específicos } \\
\text { a nivel operativo dentro de la empresa }\end{array}$ & 3.07 & 3.09 & - \\
$\begin{array}{l}\text { Hemos aumentado la subcontratación } \\
\text { de nuestras operaciones }\end{array}$ & 2.18 & 2.16 & 3.27 \\
$\begin{array}{l}\text { Se ha modificado la oferta de productos/servicios } \\
\text { para abordar nuevos clientes }\end{array}$ & 3.33 & 2.58 & $* *$ \\
Hemos tenido que bajar los precios & 2.73 & 2. \\
\hline
\end{tabular}

Nota. Diferencias estadísticamente significativas: $\left({ }^{*}\right): p<0.1 ;(* *): p<0.05 ;(* * *): p<0.01 ;(-)$ no significativa.

\section{Tabla 5.6}

Actividades operativas, según sector de actividad de la empresa

\begin{tabular}{lccccc} 
& Industria & Construcción & Comercio & Servicio & Sig. \\
\hline $\begin{array}{l}\text { Se han realizado cambios } \\
\text { específicos a nivel operativo } \\
\text { dentro de la empresa }\end{array}$ & 3.22 & 2.75 & 2.95 & 3.18 & $* *$ \\
$\begin{array}{l}\text { Hemos aumentado la subcontratación } \\
\text { de nuestras operaciones }\end{array}$ & 2.43 & 2.30 & 1.94 & 2.15 & $* * *$ \\
$\begin{array}{l}\text { Se ha modificado la oferta } \\
\text { de productos/servicios para abordar } \\
\text { nuevos clientes }\end{array}$ & 3.41 & 3.09 & 3.10 & 3.43 & $* *$ \\
$\begin{array}{l}\text { Hemos tenido que bajar los precios } \\
\text { nemo }\end{array}$ & 2.66 & 2.78 & 2.67 & 2.68 & - \\
\hline
\end{tabular}

Nota. Diferencias estadísticamente significativas: $\left.\left(^{*}\right): p<0.1 ;\left({ }^{* *}\right): p<0.05 ;{ }^{* * *}\right): p<0.01 ;(-)$ no significativa.

\subsection{Actividades estratégicas}

¿Cómo ha afectado la crisis a las actividades estratégicas de las empresas? En general, la opinión de los encuestados es que esta crisis ha generado la necesidad de adoptar medidas para gestionar la liquidez de la empresa. Los encuestados dan una valoración de 2.95 en una escala de 1 a 5 (Figura 5.3). Seguido de abandonar inversiones previstas (2.78) y gestionar un plan específico de riesgos (2.62). 
Figura 5.3

Actividades estratégicas

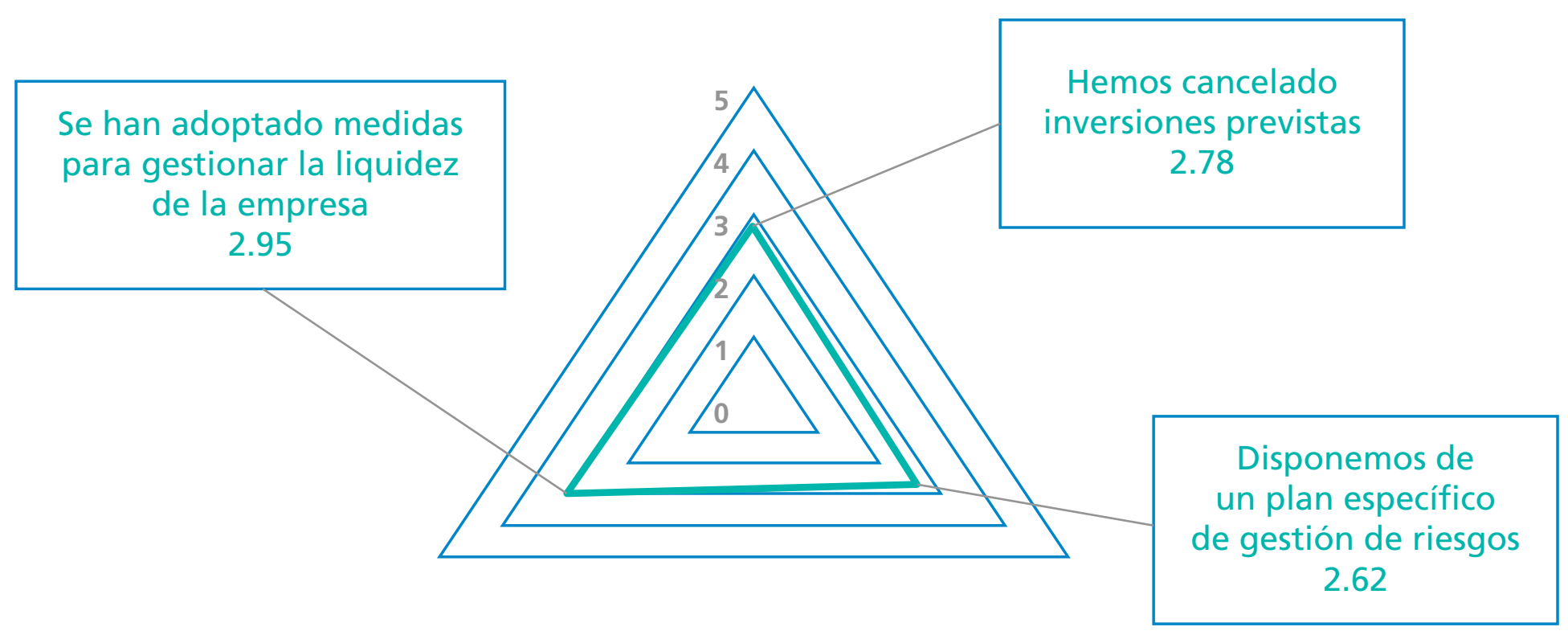

Nota. $1=$ Total desacuerdo; $5=$ Total acuerdo .

Al analizar el tamaño de la empresa (Tabla 5.7), se puede ver que las empresas medianas son las que en mayor parte han tomado medidas para gestionar la liquidez de su empresa (3.23), frente a las pequeñas (3.08) y las microempresas (2.83).

En cuanto a la edad de las empresas, vemos que las maduras son las empresas que más han gestionado la liquidez (3.03) (Tabla 5.8). Finalmente, al ver los datos por sector (Tabla 5.9), apreciamos que las empresas del sector industria son las que más han tenido que adoptar medidas para gestionar la liquidez en sus empresas (3.11), asimismo, son las que más han realizado un plan específico de riesgos (2.83).

\section{Tabla 5.7}

Actividades estratégicas, según tamaño de la empresa

\section{Micro Pequeñas Medianas Sig.}

Hemos cancelado inversiones previstas

2.78

2.77

2.77

Disponemos de un plan específico

de gestión de riesgos

$2.41 \quad 2.76 \quad 3.18 \quad * * *$

Se han adoptado medidas

para gestionar la liquidez de la empresa

$\begin{array}{llll}2.83 & 3.08 & 3.23 & * * *\end{array}$

Nota. En una escala de $1=$ Total desacuerdo a $5=$ Total acuerdo.

Diferencias estadísticamente significativas: $\left({ }^{*}\right): p<0.1 ;\left({ }^{* *}\right): p<0.05 ;(* * *): p<0.01 ;(-)$ no significativa. 
Tabla 5.8

Actividades estratégicas, según antigüedad de la empresa

\begin{tabular}{lccc} 
& $\begin{array}{c}\text { Jóvenes } \\
(\leq 10 \text { años })\end{array}$ & $\begin{array}{c}\text { Maduras } \\
(>10 \text { años })\end{array}$ & Sig. \\
$\begin{array}{l}\text { Hemos cancelado inversiones previstas } \\
\begin{array}{l}\text { Disponemos de un plan específico } \\
\text { de gestión de riesgos }\end{array}\end{array}$ & 2.75 & 2.82 & - \\
$\begin{array}{l}\text { Se han adoptado medidas para gestionar } \\
\text { la liquidez de la empresa }\end{array}$ & 2.60 & 2.64 & * \\
\hline
\end{tabular}

Nota. Diferencias estadísticamente significativas: $\left(^{*}\right): p<0.1 ;\left({ }^{* *}\right): p<0.05 ;\left({ }^{* *}\right): p<0.01 ;(-)$ no significativa.

\section{Tabla 5.9}

Actividades estratégicas, según sector de actividad de la empresa

\section{Industria Construcción Comercio Servicio Sig.}

$\begin{array}{lccccc}\text { Hemos cancelado inversiones previstas } & 2.89 & 3.16 & 2.71 & 2.81 \\ \begin{array}{l}\text { Disponemos de un plan específico } \\ \text { de gestión de riesgos }\end{array} & 2.83 & 2.39 & 2.29 & 2.70 & * * * \\ \begin{array}{l}\text { Se han adoptado medidas para } \\ \text { gestionar la liquidez de la empresa }\end{array} & 3.11 & 2.93 & 2.80 & 3.01\end{array}$

Nota. Diferencias estadísticamente significativas: $\left(^{*}\right): p<0.1 ;(* *): p<0.05 ;(* * *): p<0.01 ;(-)$ no significativa. 


\section{Actividad innovadora}

La actividad relacionada con la innovación en la MIPYME en México se muestra en la Figura 6.1; se observa el porcentaje de empresas que han realizado innovaciones en el año 2020, distinguiendo entre innovación en productos, procesos y gestión. Además, se muestra el grado de importancia de las innovaciones. En innovación de productos apreciamos que el 83.3\% de las empresas encuestadas han realizado cambios o mejoras en productos o servicios, mientras que el $76.3 \%$ ha comercializado un nuevo producto o servicio. El grado de importancia en los dos tipos de innovación de producto es muy similar.

El desarrollo de actividad innovadora en las MIPYMES mexicanas muestra en la introducción de cambios o mejoras en los procesos de productos un 83.2\%; mientras que en la adquisición de nuevos bienes de equipos lo han realizado el 75.2\% de las empresas. Si analizamos la importancia o intensidad de la innovación en aquellas empresas que han realizado la innovación, los datos muestran que las innovaciones a través de adquirir nuevos bienes de equipos (3.42) han sido menos importantes que los cambios o mejoras (3.65).

La innovación en gestión está, en general, en niveles similares de los índices anteriores. El 84.6\% ha realizado cambios en la organización relativos a dirección y gestión, el 83.5\% en la sección de compras y aprovisionamiento y el 85.3\% en el departamento comercial o de ventas. El grado de importancia de las innovaciones de gestión más relevante corresponde a las innovaciones en la dirección y gestión, y en comercial, con un valor de 3.56, seguido de las compras y aprovisionamientos 3.46. Sin embargo, el indicador con mayor ponderación de los tres tipos de innovación considerado como muy importante es en la dirección y gestión con un 32.1\% y un $29.2 \%$ en las compras como el indicador con menor valor. 


\section{Figura 6.1}

Realización de innovaciones en productos, procesos o gestión y grado de importancia

INNOVACIÓN

Productos y servicios

Cambios o mejoras en productos/servicios

Comercialización nuevos productos/servicios

Procesos

Cambios o mejoras en los procesos de producción

Adquisición de nuevos bienes de equipos

Sistemas de gestión

Dirección y gestión

Compras y aprovisionamientos

Comercial / Ventas
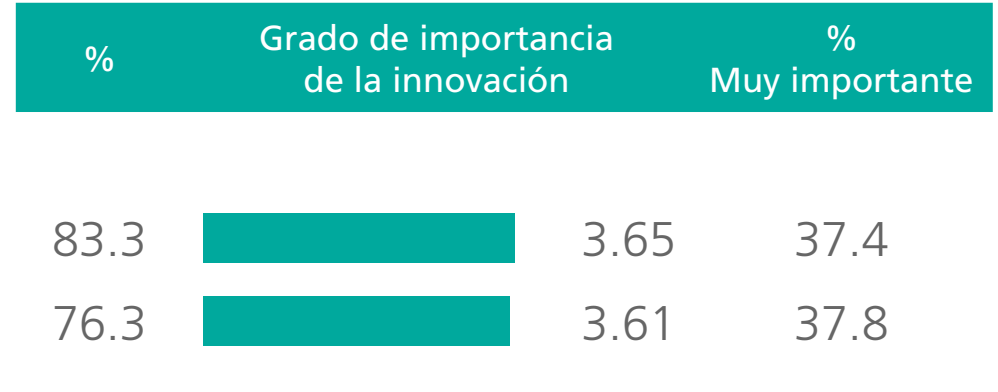

83.2

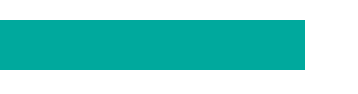

3.65

34.8

75.2

$3.42 \quad 30.4$

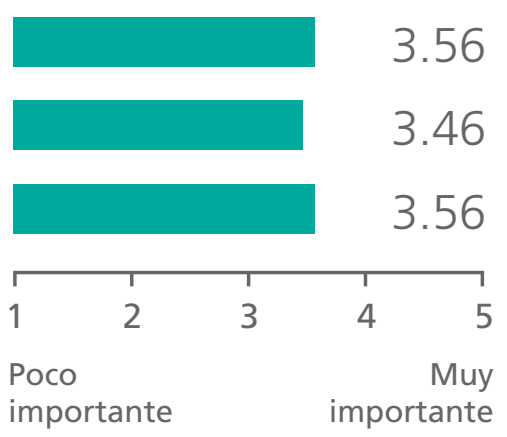

84.6

32.1

83.5

85.3

importante
29.2

31.5

Por otro lado, en la Figura 6.1, se puede observar el porcentaje de empresas que realizaron un grado muy importante en su innovación (empresas que han respondido 5 , en una escala de $1=$ poco importante a $5=$ muy importante). Así, podemos ver que el $37.4 \%$ han realizado innovaciones muy importantes en cuanto a cambios y mejoras de productos o servicios, el 30.4\% ha adquirido nuevos bienes de equipo que han supuesto un cambio muy importante y el $32.1 \%$ ha realizado innovaciones en el área de dirección y gestión.

Analizando los distintos tipos de innovación, de acuerdo con el tamaño de la empresa, se observa en la Tabla 6.1, una diferencia a favor de las empresas medianas. Mientras que el $86.2 \%$ de las empresas medianas han llevado a cabo cambios y mejoras en productos/servicios, este porcentaje disminuye a un $81.3 \%$ en las pequeñas empresas. De igual forma sucede en la comercialización de nuevos productos/servicios, donde las empresas medianas lo han realizado en un $78.8 \%$ de los casos, frente al 77.6\% de las microempresas y un 73.4\% de las pequeñas empresas $(1.2 \%$ y $5.4 \%$ de diferencia para las micro y pequeñas empresas respecto a las medianas empresas). En las innovaciones en procesos, también se observan diferencias de acuerdo con el tamaño de las empresas; el 85.1\% de las empresas 
medianas han realizado cambios o mejoras en los procesos de producción y, en el caso de las pequeñas empresas, el 82.8\%; además, el 79.9\% de las empresas medianas han realizado cambios en la adquisición de nuevos bienes de equipos y, en el caso de las pequeñas empresas, el 73.6\%. Estas diferencias a favor de las empresas de mayor tamaño, también se observan en los cambios en organización $(90.0 \%$ vs. $83.5 \%)$, cambios en compras y aprovisionamientos ( $87.6 \%$ vs. $83.5 \%$ ) y cambios en la comercialización/venta ( $90.0 \%$ vs. $83.2 \%)$. Solamente en la organización y gestión y en la comercialización/ventas existe diferencias significativas $\left(^{*}\right)$. Respecto a la importancia de las innovaciones realizadas por la empresa (Tabla 6.2), no se confirman diferencias significativas entre los tamaños analizados. Esto indica que en el caso de las empresas que realizaron innovaciones, el tamaño no explica que estas innovaciones sean más o menos importantes.

\section{Tabla 6.1}

Realización de innovaciones (\%), según tamaño de la empresa

\section{Micro Pequeñas Medianas Sig.}

Innovación en productos y servicios

Cambios o mejoras en productos/servicios

$83.4 \quad 81.3 \quad 86.2$

Comercialización nuevos productos/servicios

$\begin{array}{lll}77.6 & 73.4 & 78.8\end{array}$

Innovación en procesos

Cambios o mejoras en los procesos de producción 83.3

82.8

85.1

Adquisición de nuevos bienes de equipo

75.2

73.6

79.9

Innovación en gestión

Organización y gestión

84.0

83.5

90.0

Compras y aprovisionamientos

83.4

83.5

87.6

Comercial/ventas

85.2

83.2

90.0

Nota. Chi-Cuadrado de Pearson. Diferencias estadísticamente significativas: $(*): p<0.1 ;(* *): p<0.05$; $(* * *): p<0.01 ;(-)$ no significativa. 


\section{Tabla 6.2}

Importancia de las innovaciones, según tamaño de la empresa

\section{Micro Pequeñas Medianas Sig.}

Innovación en productos y servicios

\begin{tabular}{|c|c|c|c|c|}
\hline Cambios o mejoras en productos/servicios & 3.05 & 2.97 & 3.11 & - \\
\hline Comercialización nuevos productos/servicios & 2.82 & 2.65 & 2.80 & - \\
\hline \multicolumn{5}{|l|}{ Innovación en procesos } \\
\hline Cambios o mejoras en los procesos de producción & 3.04 & 3.05 & 3.08 & - \\
\hline Adquisición de nuevos bienes de equipo & 2.55 & 2.56 & 2.75 & - \\
\hline \multicolumn{5}{|l|}{ Innovación en gestión } \\
\hline Organización y gestión & 2.96 & 3.01 & 3.22 & - \\
\hline Compras y aprovisionamientos & 2.85 & 3.02 & 3.00 & - \\
\hline Comercial/ventas & 3.01 & 3.07 & 3.14 & - \\
\hline
\end{tabular}

Nota. En una escala de $1=$ poco importante a $5=$ muy importante. Diferencias estadísticamente significativas: $\left(^{*}\right): p<0.1 ;(* *): p<0.05 ;(* * *): p<0.01 ;(-)$ no significativa.

Respecto a si las empresas encuestadas de los diferentes sectores realizan innovación, se puede observas en la Tabla 6.3, que el 83.3\% de las empresas han realizado cambios o mejoras en productos y servicios, y el 76.7\% en la comercialización de nuevos productos. Mientras que el $83.5 \%$ ha realizado cambios o mejoras en los procesos de producción y el 75.5\% en la adquisición de nuevos bienes de equipos. Finalmente, en la innovación en gestión; los resultados obtenidos son muy similares en sus tres tipos de innovación.

En cuanto a la importancia de las innovaciones, los promedios más elevados se encuentran en la innovación de procesos con la adquisición de nuevos bienes y equipos (3.58) y en cambios o mejorar en los procesos de producción (3.05) (Tabla 6.4). Por otra parte, el comportamiento innovador con la antigüedad de las empresas arroja diferencias significativas. Solo en la innovación de productos y servicios no se demuestra diferencias significativas en los cambios o mejoras en productos y servicios (Tabla 6.5). De acuerdo con la importancia de las innovaciones con la antigüedad de la empresa, se observan resultados relevantes (diferencias significativas). Solo en los cambios o mejoras en los productos y servicios y en la organización y gestión no existe grado de significancia (Tabla 6.6). 


\section{Tabla 6.3}

Realización de innovaciones (\%)

Innovación en productos y servicios

Cambios o mejoras en productos/servicios

N.A.

Comercialización nuevos productos/servicios

76.7

N.A.

Innovación en procesos

Cambios o mejoras en los procesos de producción

N.A.

Adquisición de nuevos bienes de equipo

75.5

N.A.

Innovación en gestión

Organización y gestión

N.A.

Compras y aprovisionamientos

84.0

N.A.

Comercial/ventas

85.5

N.A.

Nota. N.A. = No aplica.

\section{Tabla 6.4}

Importancia de las innovaciones

\section{Promedio}

\section{Sig.}

Innovación en productos y servicios

Cambios o mejoras en productos/servicios

3.04

N.A.

Comercialización nuevos productos/servicios

2.77

N.A.

Innovación en procesos

Cambios o mejoras en los procesos de producción

N.A.

Adquisición de nuevos bienes de equipo

3.58

N.A.

Innovación en gestión

Organización y gestión

N.A.

Compras y aprovisionamientos

2.91

N.A.

Comercial/ventas

3.04

N.A.

Nota. N.A. = No aplica. 


\section{Tabla 6.5}

Realización de innovaciones (\%), según antigüedad de la empresa

Jóvenes
$(\leq 10$ años $)$$\quad \begin{gathered}\text { Maduras } \\ (>10 \text { años })\end{gathered} \quad$ Sig.

Innovación en productos y servicios

Cambios o mejoras en productos/servicios

84.7

81.5

Comercialización nuevos productos/servicios

80.0

71.8

$\star \star \star$

Innovación en procesos

Cambios o mejoras en los procesos de producción

86.1

80.0

Adquisición de nuevos bienes de equipo

79.3

69.4

$\star \star \star$

Innovación en gestión

Organización y gestión

87.8

79.9

Compras y aprovisionamientos

86.2

80.5

Comercial/ventas

87.6

81.8

$\star \star \star$

Nota. Chi-Cuadrado de Pearson. Diferencias estadísticamente significativas: $(*): p<0.1 ;(* *): p<0.05$; $(* * *): p<0.01 ;(-)$ no significativa.

\section{Tabla 6.6}

Importancia de las innovaciones, según antigüedad de la empresa

Jóvenes
$(\leq 10$ años $)$$\quad \begin{gathered}\text { Maduras } \\ (>10 \text { años })\end{gathered} \quad$ Sig.

Innovación en productos y servicios

Cambios o mejoras en productos/servicios

2.94

Comercialización nuevos productos/servicios

2.92

2.56

Innovación en procesos

Cambios o mejoras en los procesos de producción

2.87

$\star \star \star$

Adquisición de nuevos bienes de equipo

2.70

2.40

$\star \star$

Innovación en gestión

Organización y gestión

2.89

Compras y aprovisionamientos

3.00

2.80

Comercial/ventas

3.15

2.88

Nota. En una escala de $1=$ poco importante a $5=$ muy importante. Diferencias estadísticamente significativas: $\left(^{*}\right): p<0.1 ;\left({ }^{* *}\right): p<0.05 ;\left({ }^{* *}\right): p<0.01 ;(-)$ no significativa. 
El análisis de la innovación, tomando como referencia el sector de actividad, muestra que se han comportado de forma desigual (Tabla 6.7). En innovaciones en productos, los sectores que tienen un mayor porcentaje de empresas que han realizado comercialización de nuevos productos/servicios son el sector de servicios (80.8\%), el industrial (77.1\%), y los de menor porcentajes son el sector comercio (72.0\%) y el sector construcción (59.4\%). Igualmente, respecto a innovaciones en procesos, podemos ver que, en la realización de cambios o mejoras en los procesos, también destaca el sector industrial y de servicios, donde el $87.8 \%$ y el $87.4 \%$ de las empresas han realizado esta innovación. Por el contrario, el sector comercio es el que ha realizado menos este tipo de innovación, el 72.05\% de las empresas. En referencia a la importancia de las innovaciones, considerando el sector de actividad de la empresa, se aprecia una diferencia significativa a favor del sector servicios, en todos los tipos de innovación, menos en la comercialización/ventas (Tabla 6.8).

\section{Tabla 6.7}

Realización de innovaciones (\%), según sector de actividad

\section{Industria Construcción Comercio Servicio Sig.}

Innovación en productos y servicios

Cambios o mejoras

en productos/servicios

84.8

75.4

77.2

87.0

Comercialización nuevos

productos/servicios

77.1

59.4

72.0

80.8

Innovación en procesos

Cambios o mejoras en los procesos de producción

$\begin{array}{llll}87.8 & 76.8 & 72.05 & 87.4\end{array} * *$

Adquisición de nuevos bienes de equipo

73.4

69.6

67.2

80.1

$\star \star \star$

Innovación en gestión

Organización y gestión

85.9

82.6

76.7

89.2

Compras y aprovisionamientos

83.7

78.3

77.5

88.5

Comercial/ventas

85.2

81.2

81.4

88.5

Nota. Chi-Cuadrado de Pearson. Diferencias estadísticamente significativas: $(*): p<0.1 ;(* *): p<0.05$; $(* * *): p<0.01 ;(-)$ no significativa. 


\section{Tabla 6.8}

Importancia de las innovaciones, según sector de actividad

\section{Industria Construcción Comercio Servicio Sig.}

Innovación en productos y servicios

Cambios o mejoras

en productos/servicios

3.11

2.57

2.67

3.26

Comercialización nuevos

productos/servicios

2.82

1.93

2.59

2.91

Innovación en procesos

Cambios o mejoras en los procesos

de producción

3.24

2.68

2.42

3.27

$\star \star \star$

Adquisición de nuevos bienes de equipo

2.45

2.06

2.20

2.83

$\star \star \star$

Innovación en gestión

Organización y gestión

3.08

2.68

2.51

3.27

$\star \star \star$

Compras y aprovisionamientos

2.94

2.54

2.59

3.08

$\star \star \star$

Comercial/ventas

3.06

2.68

2.90

3.15

Nota. En una escala de $1=$ poco importante a $5=$ muy importante. Diferencias estadísticamente significativas: $\left(^{*}\right): p<0.1 ;\left({ }^{* *}\right): p<0.05 ;\left({ }^{* *}\right): p<0.01 ;(-)$ no significativa. 


\section{Acceso al financiamiento}

En este apartado se analiza el financiamiento de las MIPymEs. Para ello, se ha preguntado si la empresa ha intentado acceder a líneas de financiamiento en la actualidad, así como la decisión del banco en caso de haberla solicitado. La Figura 7.1 muestra que solo el 18.5\% de las MIPYMES ha solicitado líneas de financiamiento de entidades de crédito, mientras que el $30.3 \%$ no ha realizado la solicitud, porque no lo necesita, y el $26.9 \%$ no lo ha solicitado, porque se autofinancia. Por otra parte, el 24.4\% declara que no ha intentado acceder a líneas de financiamiento, pese a necesitarlo, porque cree que no lo conseguiría, es decir, las empresas se autorracionan porque están desanimadas (borrower discouragement).

\section{Figura 7.1}

¿Su empresa ha intentado acceder a líneas de financiamiento de entidades de crédito en la actualidad?

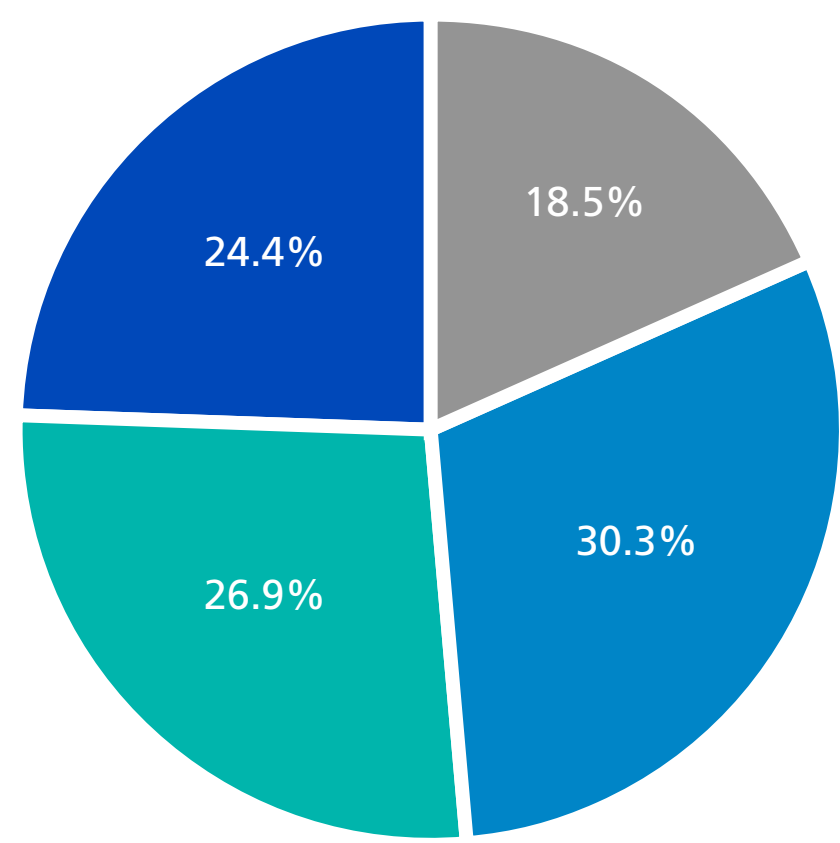

Sí $\square$ No necesita $\square$ Se Autofinancia

No conseguiría 
La Figura 7.2 muestra el resultado de las negociaciones entre las entidades de crédito y aquellas empresas que han intentado contratar líneas de financiamiento. Se puede apreciar que el 29.2\% de los participantes declara que la entidad de crédito no ha querido concederles el financiamiento o ellos no la han aceptado. Para un 15.5\%, la solicitud se encuentra en trámite. El resto de las solicitudes de financiamiento han sido aceptadas por las entidades de crédito en las mismas condiciones que en años anteriores (39.3\%) o en peores condiciones (16.0\%).

\section{Figura 7.2}

En caso de haberlo solicitado

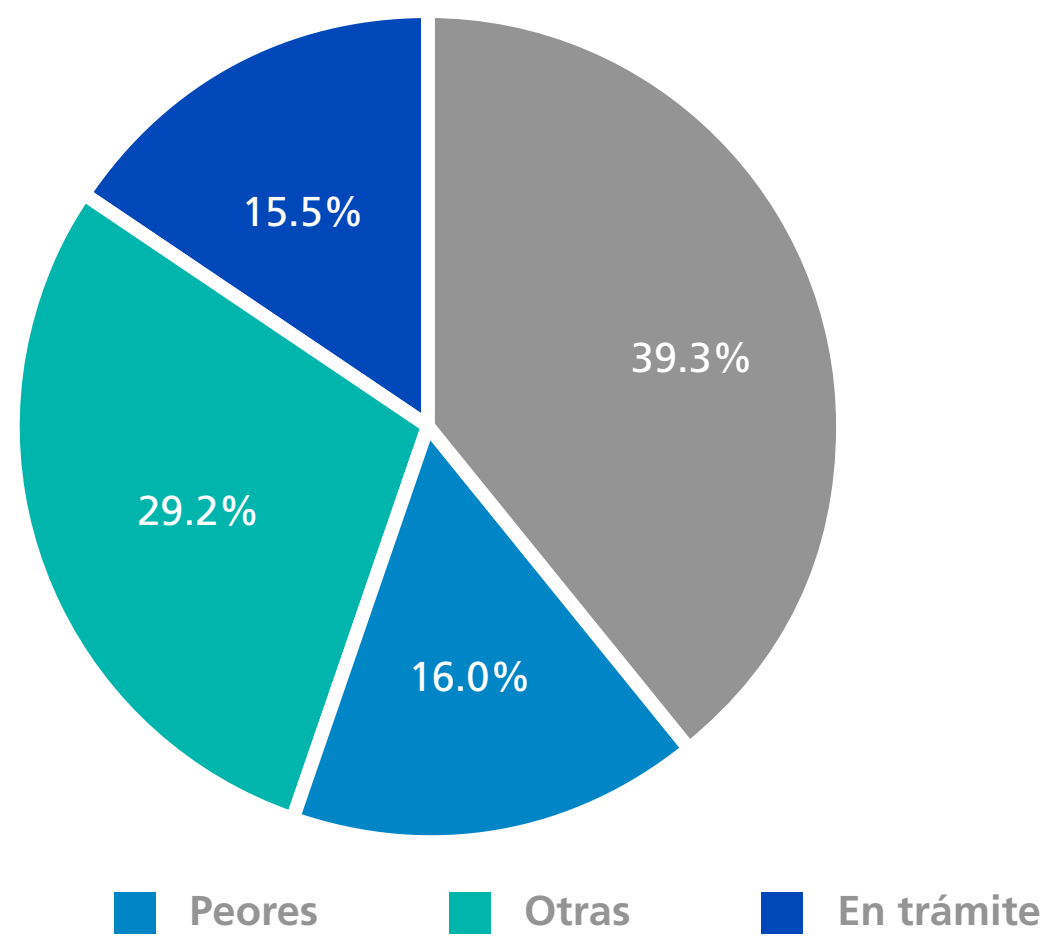

Nota. Otras $=$ No se le ha concedido o no se ha aceptado.

Las diferencias en la solicitud y acceso al financiamiento se analizan considerando el tamaño, la antigüedad y el sector de actividad de la empresa. Por lo que respecta al tamaño (Tabla 7.1), se aprecian diferencias estadísticamente significativas en cuanto al porcentaje de empresas que han intentado acceder a líneas de financiamiento de entidades de crédito, esto se puede observar con la baja solicitud de financiamiento, con el 30.2\% de las empresas medianas, frente a solo el 14.1\% de las microempresas. Esta baja participación en el financiamiento se explica debido a que la empresa no esta invirtiendo y no la necesita; así se observa en las empresas medianas con el $25.7 \%$, frente a las microempresas con $33.2 \%$. Sin embargo, si analizamos el panel B que refleja el resultado del acceso al financiamiento, el factor 
de no concederles muestra resultados estadísticamente significativos, afectando principalmente a la microempresa con el $34 \%$.

Los resultados obtenidos a partir de la segmentación (Tabla 7.2) muestran que el 18.5\% de las empresas solicita financiamiento; el 30.3\% manifiesta que no la necesita, otro $26.9 \%$ se financia con recursos propios y, por último, el $24.4 \%$ teme no obtener ningún financiamiento. En el panel B, se observa que el 39.9\% manifiesta que las condiciones no han cambiado con respecto al año anterior; no solamente conservan las mismas condiciones, si no que se ha endurecido una vez autorizado el crédito, así lo manifiestan el 5.5\%.

En cuanto a la antigüedad de la empresa, la Tabla 7.3 muestra que las empresas maduras son las que más solicitan créditos a las entidades financieras. Así, el 21.5\% de las maduras solicitaron un crédito, frente al 14.1\% de las jóvenes (Panel A). La baja solicitud de las empresas jóvenes se debe a que no están invirtiendo o no la necesitan, con el 33.2\%, frente al $26.5 \%$ de empresa maduras; por otra parte, una vez solicitado el crédito, las empresas jóvenes se ven más limitadas para su obtención. Así, se aprecian diferencias estadísticamente significativas en cuanto al porcentaje de empresas que no han querido concederles el financiamiento, con el 34.0\% de las empresas jóvenes y $20.0 \%$ de las maduras. Si consiguieran el financiamiento, el 5\% no lo acepta porque las condiciones se han endurecido para ambos tipos de empresa.

\section{Tabla 7.1}

Financiamiento de la empresa, según el tamaño

\section{Micro Pequeñas Medianas Sig.}

Panel A. Solicitud de financiamiento

\begin{tabular}{|c|c|c|c|c|}
\hline Sí, la empresa ha solicitado financiamiento (\%) & 14.1 & 21.5 & 30.2 & \\
\hline $\begin{array}{l}\text { No, porque la empresa no está invirtiendo } \\
\text { y no lo necesita }(\%)\end{array}$ & 33.2 & 26.5 & 25.7 & $* * *$ \\
\hline $\begin{array}{l}\text { No, porque la empresa se está autofinanciando } \\
\text { y no lo necesita (\%) }\end{array}$ & 24.6 & 29.3 & 31.7 & \\
\hline $\begin{array}{l}\text { No, porque pese a necesitarlo la empresa } \\
\text { teme no obtenerlo }(\%)\end{array}$ & 28.1 & 22.7 & 12.4 & \\
\hline
\end{tabular}


Micro Pequeñas Medianas Sig.

Panel B. Acceso a financiamiento

Se le ha concedido con las mismas condiciones

que en años anteriores (\%)

$\begin{array}{lll}28.0 & 45.0 & 52.5 \\ 17.0 & 16.7 & 13.6 \\ 34.0 & 20.0 & 10.2 \quad * * \\ 5.0 & 5.0 & 6.8 \\ 16.0 & 13.3 & 16.9\end{array}$

Se le ha concedido, aunque las condiciones

se han endurecido (\%)

No han querido concederles el financiamiento (\%)

Se le ha concedido, pero la empresa no lo ha aceptado, porque las condiciones se han endurecido (\%)

Está en trámite (\%)

Nota. Chi-Cuadrado de Pearson. Diferencias estadísticamente significativas: $\left.{ }^{*}\right): p<0.1 ;(* *): p<0.05$; $(* * *): p<0.01 ;(-)$ no significativa.

\section{Tabla 7.2}

Financiamiento de la empresa, según la segmentación

$\%$

Sig.

Panel A. Solicitud de financiamiento

Sí, la empresa ha solicitado financiamiento (\%)

18.5

No, porque la empresa no está invirtiendo

y no lo necesita (\%)

30.3

26.9

y no lo necesita (\%)

No, porque pese a necesitarlo la empresa teme no obtenerlo (\%)

24.4

Panel B. Acceso a financiamiento

Se le ha concedido con las mismas condiciones

que en años anteriores (\%)

39.3

Se le ha concedido, aunque las condiciones

se han endurecido (\%)

No han querido concederles el financiamiento (\%)

23.7

N.A.

Se le ha concedido, pero la empresa no lo ha aceptado, porque las condiciones se han endurecido (\%)

Está en trámite (\%)

15.5

Nota. N.A. = No aplica. 
Tabla 7.3

Financiamiento de la empresa, según la antigüedad

$\begin{array}{cc}\text { Jóvenes } & \text { Maduras } \\ \text { ( } \leq 10 \text { años }) & (>10 \text { años })\end{array}$

Panel A. Solicitud de financiamiento

Sí, la empresa ha solicitado financiamiento (\%)

14.1

21.5

No, porque la empresa no está invirtiendo

y no lo necesita (\%)

No, porque la empresa se está autofinanciando

y no lo necesita (\%)

No, porque pese a necesitarlo la empresa

teme no obtenerlo (\%)

Panel B. Acceso a financiamiento

Se le ha concedido con las mismas condiciones

que en años anteriores (\%)

33.2

26.5

24.6

29.3

28.1

22.7

Se le ha concedido, aunque las condiciones

se han endurecido (\%)

No han querido concederles el financiamiento (\%)

Se le ha concedido, pero la empresa no lo ha aceptado,

porque las condiciones se han endurecido (\%)

Está en trámite (\%)

Nota. N.A. = No aplica.

Por último, respecto al sector de actividad, no se encuentran diferencias significativas en la solicitud de financiamiento (Tabla 7.4, Panel A). El sector comercial y de servicios son los sectores donde las empresas solicitan menos solicitudes de financiamiento a las entidades financieras. Así, solo el 16.6\% de las empresas comerciales solicitaron financiamiento y el 17.5\% de servicios, frente al 31.9\% del sector comercial y $29.4 \%$ del sector de servicios que no lo solicitaron por no estar invirtiendo. En el resto de los sectores analizados, como industria y construcción, ocurre justamente lo contrario. No surgiendo diferencias significativas entre los sectores en el resultado de la solicitud de financiamiento (Panel B), destacando el sector servicios con un $24.7 \%$, tanto en el rechazo a su solicitud como del otorgamiento de financiamiento; este último, con condiciones más estrictas. 
Tabla 7.4

Financiamiento de la empresa, según sector de actividad

Industria Construcción Comercio Servicio Sig.

Panel A. Solicitud de financiamiento

Sí, la empresa ha solicitado

financiamiento (\%)

$\begin{array}{llll}21.9 & 29.4 & 16.6 & 17.5\end{array}$

No, porque la empresa no está

invirtiendo y no lo necesita (\%)

$\begin{array}{llll}31.1 & 27.9 & 31.9 & 29.4\end{array}$

No, porque la empresa se está

autofinanciando y no lo necesita (\%)

$\begin{array}{llll}24.6 & 22.1 & 28.8 & 27.6\end{array}$

No, porque pese a necesitarlo

la empresa teme no obtenerlo (\%)

$22.4 \quad 20.6 \quad 22.7 \quad 25.5$

Panel B. Acceso a financiamiento

Se le ha concedido con las mismas

condiciones que en años anteriores (\%)

44.4

27.8

51.4

38.4

Se le ha concedido, aunque las

condiciones se han endurecido (\%)

8.3

16.7

16.2

24.7

No han querido concederles

el financiamiento (\%)

22.2

22.2

16.2

24.7

Se le ha concedido, pero la empresa no lo ha aceptado, porque las condiciones se han endurecido (\%)

11.1

2.7

Está en trámite (\%)

16.7

22.2

16.2

9.6

Nota. Chi-Cuadrado de Pearson. Diferencias estadísticamente significativas: $(*): p<0.1 ;(* *): p<0.05$; $(* * *): p<0.01 ;(-)$ no significativa.

El análisis del acceso al financiamiento bancario debe completarse con la discusión sobre las condiciones de dicho financiamiento. Nos referimos a términos contractuales tales como costo y volumen de la línea de financiamiento, las comisiones y gastos de la operación, las garantías y avales que deben aportarse y el plazo de devolución de los recursos. Asimismo, analizamos un aspecto clave de la negociación como es el tiempo de respuesta de la entidad financiera. En este apartado, analizamos la evolución de estos elementos a lo largo del 2020, periodo de 
la pandemia (Figura 7.3). Medido en una escala de 1 (muy desfavorable) a 5 (muy favorable), podemos observar que la mayoría de las condiciones se han mantenido estables. Los elementos que mejor han evolucionado fueron el volumen de financiamiento que ofrecen las entidades, con una puntuación media de 2.59, situándose a continuación el tiempo de respuesta de la entidad financiera con 2.56, el plazo exigido para la devolución del financiamiento, así como el costo del financiamiento, ambos con 2.55. Los términos con una evolución menos favorable han sido las garantías exigidas (2.53) y las comisiones que se exigen (2.51).

\section{Figura 7.3}

A lo largo del 2020 ¿Cómo cree que han evolucionado las siguientes variables?

El volumen del financiamiento que le ofrecen

Los gastos y comisiones que se exigen

Las garantías y vales que necesitan para acceder al financiamiento

El costo del financiamiento

El tiempo entre la solicitud del financiamiento y la respuesta de la entidad financiera

El plazo exigido de la devolución
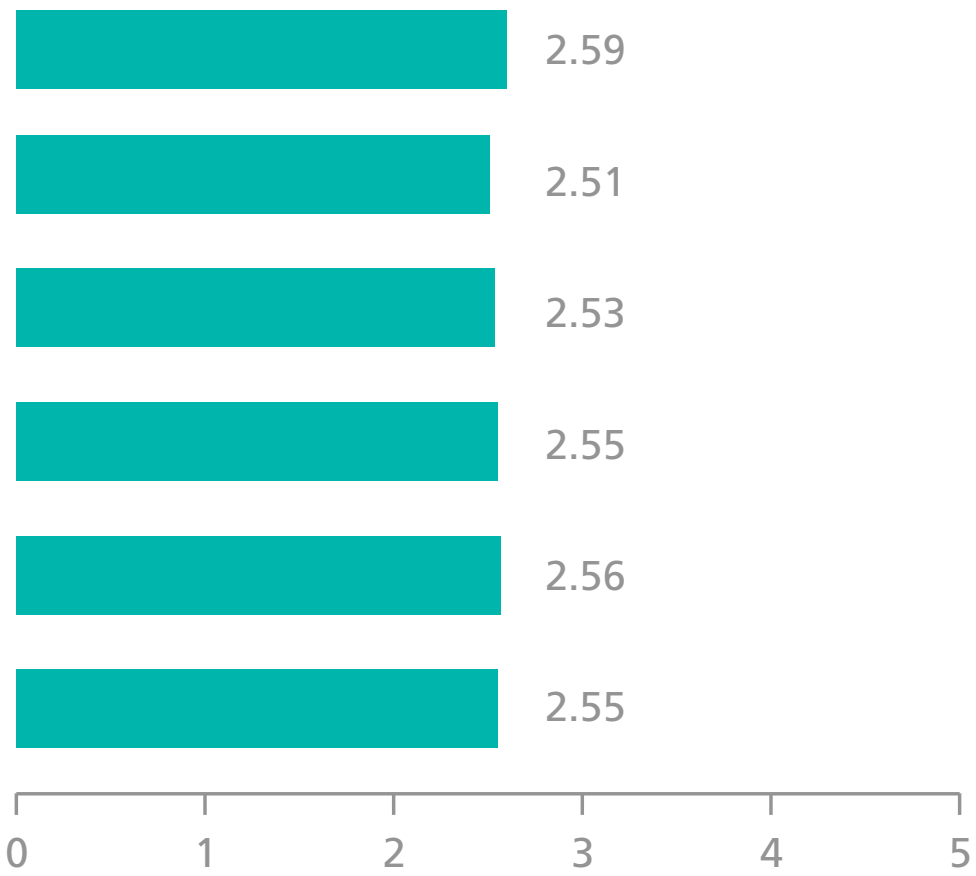

Nota. 1 = Muy desfavorable; 5 = Muy favorable.

En cuanto a las condiciones de financiamiento, surge una diferencia significativa en todos los indicadores, así es para las empresas medianas en cuanto al volumen (2.97), los gastos y comisiones exigidos (2.78), garantías y costos de financiación (2.81), así como el tiempo de resolución de la solicitud y el vencimiento que ofrecen las entidades financieras, ambas con 2.75 (Tabla 7.5), en una escala de 1 a 5, seguidas por las pequeñas y microempresas. Estos resultados guardan congruencia con las condiciones de financiamiento (Tabla 7.6), que va desde 2.59 en el volumen del financiamiento ofrecido hasta 2.51 en gastos y comisiones exigidos. 
Tabla 7.5

Evolución en las condiciones de financiamiento, según tamaño de la empresa

\begin{tabular}{lcccc} 
& Micro & Pequeñas & Medianas & Sig. \\
El volumen de financiamiento ofrecido & 2.44 & 2.69 & 2.97 & $* * *$ \\
Los gastos y comisiones exigidos & 2.41 & 2.59 & 2.78 & $* * *$ \\
Las garantías y avales necesarios & 2.44 & 2.55 & 2.81 & $* * *$ \\
El costo del financiamiento & 2.45 & 2.60 & 2.82 & $* * *$ \\
El tiempo de resolución de la solicitud & 2.49 & 2.60 & 2.75 & $* *$ \\
El vencimiento del financiamiento & 2.45 & 2.66 & 2.75 & $* * *$ \\
\hline
\end{tabular}

Nota. En una escala de $1=$ Muy desfavorable a $5=$ Muy favorable. Diferencias estadísticamente significativas: $(*): p<0.1 ;\left(^{* *}\right): p<0.05 ;(* * *): p<0.01 ;(-)$ no significativa.

\section{Tabla 7.6}

\section{Evolución en las condiciones de financiamiento (promedio)}

\begin{tabular}{lcc} 
& Promedio & Sig. \\
\hline El volumen de financiamiento ofrecido & 2.59 & N.A. \\
Los gastos y comisiones exigidos & 2.51 & N.A. \\
Las garantías y avales necesarios & 2.53 & N.A. \\
El costo del financiamiento & 2.55 & N.A. \\
El tiempo de resolución de la solicitud & 2.56 & N.A. \\
El vencimiento del financiamiento & 2.55 & N.A. \\
\hline
\end{tabular}

Nota. En una escala de $1=$ Muy desfavorable a $5=$ Muy favorable. N.A. $=$ No aplica.

Respecto a la antigüedad de la empresa, esta tiene también un efecto limitado sobre la evolución de las condiciones del financiamiento (Tabla 7.7). Surge una diferencia significativa en dos indicadores; así es al analizar los gastos y comisiones exigidos en empresas maduras (2.41) contra los de las empresas jóvenes (2.57); también en cuanto a las garantías y avales necesarios en empresas maduras (2.43) contra los de empresas jóvenes (2.58). Las empresas más maduras piensan que esta condición es más desfavorable frente a las empresas mas jóvenes. Sin embargo, tan solo surge una diferencia significativa al analizar el vencimiento de financiamiento 
ofrecido en las condiciones de financiamiento (Tabla 7.8). En las empresas del sector de la construcción, hay que considerar que son menos favorecidas en el vencimiento del financiamiento con respecto a los sectores industrial, comercial y de servicios. Los demás indicadores no muestran diferencias significativas en cuanto a las condiciones de financiamiento.

\section{Tabla 7.7}

Evolución en las condiciones de financiamiento, según antigüedad de las empresas

\begin{tabular}{lccc} 
& $\begin{array}{c}\text { Jóvenes } \\
(\leq 10 \text { años })\end{array}$ & $\begin{array}{c}\text { Maduras } \\
(>10 \text { años })\end{array}$ & Sig. \\
\hline El volumen de financiamiento ofrecido & 2.57 & 2.60 & - \\
Los gastos y comisiones exigidos & 2.57 & 2.41 & $*$ \\
Las garantías y avales necesarios & 2.58 & 2.43 & - \\
El costo de financiamiento & 2.57 & 2.50 & - \\
El tiempo de resolución de la solicitud & 2.57 & 2.54 & - \\
El vencimiento del financiamiento & 2.54 & 2.57 & - \\
\hline
\end{tabular}

Nota. En una escala de $1=$ Muy desfavorable a $5=$ Muy favorable. Diferencias estadísticamente significativas: $(*): p<0.1 ;(* *): p<0.05 ;(* * *): p<0.01 ;(-)$ no significativa.

\section{Tabla 7.8}

Evolución en las condiciones del financiamiento, según sector de actividad

\begin{tabular}{lccccc} 
& Industria & Construcción & Comercio & Servicio & Sig. \\
El volumen del financiamiento ofrecido & 2.62 & 2.42 & 2.65 & 2.58 & - \\
Los gastos y comisiones exigidos & 2.61 & 2.33 & 2.50 & 2.51 & - \\
Las garantías y avales necesarios & 2.54 & 2.24 & 2.58 & 2.54 & - \\
El costo del financiamiento & 2.55 & 2.27 & 2.57 & 2.57 & - \\
El tiempo de resolución de la solicitud & 2.60 & 2.21 & 2.63 & 2.57 & - \\
El vencimiento del financiamiento & 2.61 & 2.33 & 2.61 & 2.56 & * \\
\hline
\end{tabular}

Nota. En una escala de $1=$ Muy desfavorable a $5=$ Muy favorable. Diferencias estadísticamente significativas: $(*): p<0.1 ;(* *): p<0.05 ;(* * *): p<0.01 ;(-)$ no significativa. 


\section{Indicadores de rendimiento}

$\mathrm{Al}$ analizar el rendimiento de las MIPYMES frente a sus competidores y el tamaño de la empresa participante (Tabla 8.1), se logra encontrar diferencias significativas a favor de las medianas empresas en los factores relacionados con ofrecer productos de mayor calidad (3.87\%), disponer de procesos internos más eficientes (3.74\%), adaptarse mejor a los cambios en el mercado (3.68\%), estar creciendo más (3.45\%) y ser más rentables (3.41\%) que las micro y pequeñas empresas. Contrariamente, las microempresas tienen un menor absentismo laboral (3.02\%) que las pequeñas y medianas empresas; asimismo, las microempresas cuentan con un mayor porcentaje de clientes satisfecho (3.99\%). Con relación a la satisfacción de los empleados, las empresas medianas (3.67\%) presentan un mayor porcentaje.

\section{Tabla 8.1}

Rendimiento frente a sus competidores, según tamaño de la empresa

\begin{tabular}{lcccc} 
& Micro & Pequeñas & Medianas & Sig. \\
Ofrece productos de mayor calidad & 3.75 & 3.75 & 3.87 & - \\
Dispone de procesos internos más eficientes & 3.61 & 3.66 & 3.74 & - \\
Cuenta con clientes más satisfechos & 3.99 & 3.95 & 3.98 & - \\
Se adapta antes a los cambios en el mercado & 3.66 & 3.69 & 3.68 & - \\
Está creciendo más & 3.18 & 3.29 & 3.45 & $* \star$ \\
Es más rentable & 3.23 & 3.33 & 3.41 & $*$ \\
Tiene empleados más satisfechos/motivados & 3.58 & 3.67 & 3.52 & - \\
Tiene un menor absentismo laboral & 3.02 & 3.17 & 3.16 & - \\
\hline
\end{tabular}

Nota. En una escala de $1=$ Total desacuerdo a $5=$ Total acuerdo. Diferencias estadísticamente significativas: $(*): p<0.1 ;(* *): p<0.05 ;(* * *): p<0.01 ;(-)$ no significativa. 


\section{Tabla 8.2}

Rendimiento frente a sus competidores (promedio)

\begin{tabular}{lcc} 
& Promedio & Sig. \\
Ofrece productos de mayor calidad & 3.77 & N.A. \\
Dispone de procesos internos más eficientes & 3.64 & N.A. \\
Cuenta con clientes más satisfechos & 3.97 & N.A. \\
Se adapta antes a los cambios en el mercado & 3.67 & N.A. \\
Está creciendo más & 3.25 & N.A. \\
Es más rentable & 3.28 & N.A. \\
Tiene empleados más satisfechos/motivados & 3.60 & N.A. \\
Tiene un menor absentismo laboral & 3.08 & N.A. \\
\hline
\end{tabular}

Nota. En una escala de $1=$ Total desacuerdo a $5=$ Total acuerdo. N.A. $=$ No aplica.

En cuanto al rendimiento de las MIPYMES frente a sus competidores, según su antigüedad (Tabla 8.3), se puede apreciar que las empresas jóvenes consideran estar mejor posicionadas que las maduras, porque disponen de procesos internos más eficientes (3.66), están creciendo más (3.30), son más rentables (3.31) y tienen un menor absentismo laboral (3.08).

\section{Tabla 8.3}

Rendimiento frente a sus competidores, según antigüedad de la empresa

\begin{tabular}{lccc} 
& Jóvenes & Maduras & Sig. \\
Ofrece productos de mayor calidad & 3.78 & 3.76 & - \\
Dispone de procesos internos más eficientes & 3.66 & 3.61 & - \\
Cuenta con clientes más satisfechos & 4.02 & 3.92 & $* *$ \\
Se adapta antes a los cambios en el mercado & 3.67 & 3.67 & - \\
Está creciendo más & 3.30 & 3.18 & - \\
Es más rentable & 3.31 & 3.23 & - \\
Tiene empleados más satisfechos/motivados & 3.67 & 3.48 & $* * *$ \\
Tiene un menor absentismo laboral & 3.08 & 3.06 & - \\
\hline
\end{tabular}

Nota. En una escala de $1=$ Total desacuerdo a $5=$ Total acuerdo. Diferencias estadísticamente significativas: $(*): p<0.1 ;(* *): p<0.05 ;(* * *): p<0.01 ;(-)$ no significativa. 
Finalmente, con relación al sector de actividad, los datos mostraron diferencias estadísticamente significativas en algunos indicadores (Tabla 8.4). Las empresas de industria (4.01) y de construcción (4.07) cuentan con clientes más satisfechos. Las empresas de industria tienen un mayor crecimiento (3.31), son más rentables (3.35), pero siguen manteniendo un crecimiento elevado de absentismo laboral (3.19), en comparación del resto de los sectores (construcción, 3.03; comercio, 3.02; servicios, 3.05).

\section{Tabla 8.4}

Rendimiento frente a sus competidores, según sector de actividad

\section{Industria Construcción Comercio Servicio Sig.}

Ofrece productos de mayor calidad

3.89

3.71

3.62

3.74

Dispone de procesos internos

más eficientes

3.72

3.78

3.38

3.69

Cuenta con clientes más satisfechos

4.01

4.07

3.84

3.98

Se adapta antes a los cambios

en el mercado

3.69

3.88

3.53

3.66

Está creciendo más

3.31

3.04

3.19

3.21

Es más rentable

3.35

3.14

3.15

3.26

Tiene empleados

más satisfechos/motivados

3.59

3.45

3.52

3.63

Tiene un menor absentismo laboral

3.19

3.03

3.02

3.05

Nota. En una escala de $1=$ Total desacuerdo a $5=$ Total acuerdo. Diferencias estadísticamente significativas: $\left({ }^{*}\right): p<0.1 ;\left(^{* *}\right): p<0.05 ;(* * *): p<0.01 ;(-)$ no significativa. 


\section{Resumen ejecutivo}

En este apartado se presentan las principales conclusiones de este estudio, realizado a 1416 empresas mexicanas, sobre el impacto económico de la crisis provocada por la COVID-19.

\section{Características generales de las empresas encuestadas}

- El $55.7 \%$ son microempresas, el $23.9 \%$ son pequeñas y $20.4 \%$ son medianas.

- La antigüedad media de las empresas es de 12.7 años.

- El 70.2\% son empresas familiares.

- El 68.6\% están dirigidas por gerentes con estudios universitarios.

- En el 34.2\% de los casos, la dirección de la empresa es gestionada por mujeres.

- Como consecuencia de la COVID-19, el 18.8\% de las MIPYMES utilizan el teletrabajo y solo el $28.7 \%$ prevé que lo seguirá utilizando, aunque finalice la pandemia.

- El 22\% de las MIPYMES encuestadas obtuvieron algún tipo de apoyo debido a la COVID-19.

\section{Impacto económico de la crisis}

\section{Empleo}

El empleo en 2020 se vio afectado negativamente en la mayoría de las MIPYMES mexicanas, como consecuencia de la crisis causada por Covid-19. Los resultados muestran que el empleo disminuyó en el 34.4\% de las empresas encuestadas, que se mantuvo en el 35.1\% de ellas, mientras que un 30.4\% manifestó que el empleo 
aumentó. A pesar de la afectación sufrida en 2020, estas empresas consideraron que en 2021 el empleo mejorará, ya que un 58.7\% espera aumentar el número de trabajadores y un 33.5\% espera mantener a los que tiene actualmente; solo un 7.8\% espera reducir su plantilla laboral.

Al analizar los resultados de la evolución del empleo en 2019 y 2020, según el tamaño de la empresa, se observa que las empresas de todos los tamaños tuvieron un resultado desfavorable en cuanto al empleo, siendo las pequeñas empresas las más afectadas (saldo de expectativas: -5.9), pero también es el grupo donde hay mejores expectativas para 2021 (saldo de expectativas: 28.7). Agrupando a las empresas por su antigüedad, se observó que las empresas maduras son las que resultaron más afectadas negativamente (saldo de expectativas: -17.1) con un saldo de expectativas de mejora para 2021 de 11.4, mientras que las jóvenes tuvieron un saldo de expectativas positivo de 4.8 y una expectativa de mejora para 2021 de 20.8. El análisis por sector de actividad demostró que el sector de la construcción fue el de mayor afectación negativa (saldo de expectativas: -17.9), seguido del sector comercio (saldo de expectativas: -14.4), industria (saldo de expectativas: -6.2) y servicios (saldo de expectativas: -07.0$)$

\section{Ventas}

Las ventas de las MIPYMES mexicanas han sido uno de los aspectos económicos con mayor afectación negativa, como consecuencia de la disminución de la actividad económica causada por la emergencia sanitaria. Más de la mitad de estas vieron reducidas sus ventas (51.9\%) y otra parte importante no tuvo crecimiento (28\%), únicamente una pequeña proporción incrementó sus ventas (20.2\%). Al analizar los resultados agrupando por tamaño de la empresa, antigüedad y sector de actividad, se puede observar que las más afectadas fueron las pequeñas empresas (saldo de expectativas: -33.9), las empresas maduras (saldo de expectativas: -39.7) y las empresas del sector de la construcción (saldo de expectativas: -42.0).

Igual que el empleo, la mayoría de las MIPYMEs consideró que las ventas mejorarán para el 2021, observando una mejora progresiva del primer semestre al segundo semestre de ese año. Las expectativas de ventas más favorables para el 2021 las presentan las empresas medianas (saldo de expectativas 1er y 2do semestre: 51.2 y 76.8), las empresas jóvenes (saldo de expectativas $1^{\circ}$ y $2^{\circ}$ semestre: 51.9 y 72.7) y las empresas de servicios (saldo de expectativas $1^{\circ}$ y $2^{\circ}$ semestre: 50.1 y 74.5 ). 


\section{Indicadores económicos y financieros}

El impacto negativo de la pandemia afectó a varios indicadores económicos y financieros de la mayoría de las MIPYMES mexicanas, con los siguientes grados de importancia (en una escala de 1 a 5):

- Nivel de facturación: el 59.9\% se vio afectado negativamente, con un grado de importancia de 2.94 .

- Rentabilidad: el $61.8 \%$ de las empresas se vio afectado negativamente, con un grado de importancia de 2.99 .

- Productividad: el 62.8\% se vio afectado negativamente, con un grado de importancia de 2.99.

- Realización de inversiones: el 58.8\% de las empresas han reducidos sus inversiones con una importancia media de 3.06.

- Nivel de deuda: el 55.7\% se han visto afectadas negativamente, con un grado de importancia de 2.89 .

- Nivel de liquidez: el 61.3\% de empresas afectadas, con un impacto de 2.88 .

Al analizar los datos por tamaño de la empresa, se encontró que las pequeñas empresas fue el grupo más afectado negativamente en sus indicadores financieros, seguidas de las medianas y, por último, las microempresas, excepto en el nivel de deuda (donde la microempresa tuvo la mayor afectación) y en el nivel de liquidez (donde las medianas empresas fueron las más afectadas). En cuanto a la antigüedad, se observó que los indicadores de rentabilidad, productividad, realización de inversiones y nivel de liquidez se afectó negativamente mayormente en las empresas jóvenes, mientras que los indicadores de facturación y nivel de deuda se afectaron mayormente en empresas maduras. Respecto al sector de actividad, en general, todos los sectores se han visto más afectados negativamente en todos los indicadores, siendo el sector más afectado el de la construcción.

\section{Internacionalización}

El 17.9\% de las empresas encuestadas han realizado, a lo largo de 2020, ventas a mercados internacionales. La intensidad media de las ventas a mercados internacionales sobre el total de las ventas de las empresas exportadoras fue del 37.4\%.

La crisis ha afectado de manera importante a la internacionalización de las empresas mexicanas. En el 53.4\% de las empresas, la crisis impactó negativamente en su nivel de facturación, con un grado de importancia de 2.74 (en una escala de 
1 a 5). También se vio afectado el número de países de destino de la internacionalización; el 43.0\% de las empresas señalaron que se redujo el número de países de destino de sus exportaciones como consecuencia de la crisis, con un grado de importancia de 2.5.

Contrariamente, la crisis ha podido afectar positivamente a determinadas empresas a lo largo del 2020. Así, el 14.6\% de las empresas encuestadas señala que tuvo un incremento en su nivel de facturación en los mercados internacionales, con un grado de importancia de 2.61, y el 14.8\% amplió el número de países de destino en su internacionalización, con un grado de importancia de 2.75 .

\section{Impacto sobre la organización de la empresa}

La crisis sanitaria también ha impactado en la gestión de las actividades de las MIPYMES mexicanas. Las actividades se han clasificado en: (a) actividades con clientes y proveedores, (b) actividades operativas y (c) actividades estratégicas.

\section{Actividades con clientes y proveedores}

La crisis ocasionada por la COVID-19 ha afectado a las MIPYMES, principalmente en la cadena de suministros por parte de sus proveedores (grado de importancia 3.07, en una escala de 1 a 5 ), en los proveedores que han endurecido sus condiciones de pago (2.82), en los plazos de pago de los clientes que se han hecho más largos (2.72), y también ha provocado la cancelación de pedidos por parte de sus clientes (2.66). Con un menor impacto también han sufrido pérdidas por impago de clientes (2.47).

\section{Actividades operativas}

A consecuencia de la crisis, las MIPYMES mexicanas han tenido que modificar su oferta de productos o servicios para abordar nuevos clientes (3.30), también han tenido que realizar cambios específicos a nivel operativo para adaptarse a la situación de la crisis (3.08) y han tenido que bajar precios (2.67). La subcontratación de sus operaciones ha tenido un impacto muy bajo (2.17).

\section{Actividades estratégicas}

Para sortear la crisis con una visión estratégica, en primera instancia, las MIPYMES se han visto en la necesidad de adaptar medidas para gestionar la liquidez de la empresa (2.95), seguidamente de abandonar inversiones previstas (2.78) y, por último, de hacer planes de gestión de riesgos o de contingencias (2.62). 


\section{Actividad innovadora}

La actividad innovadora de las MIPYMES en México, durante el año 2020, se observa principalmente en nuevos cambios o mejoras en el aspecto comercial o de ventas (85.3\%), nuevos cambios o mejoras en organización o gestión (84.6\%) y en cambios o mejoras en productos o servicios (83.3\%).

Sin embargo, el grado de importancia de cada una de las actividades de innovación se refleja, principalmente, en cambios o mejoras en los procesos de producción (3.65) y cambios o mejoras en productos o servicios (3.65), dando menor importancia a la adquisición de nuevos bienes de equipos (3.42).

La antigüedad de la empresa es determinante en la innovación, las empresas jóvenes ( $\leq 10$ años) son más proclives a la actividad innovadora, en comparación con aquellas empresas con una antigüedad mayor de 10 años. Dicha innovación se observa en mayor medida en las empresas jóvenes, en la realización de nuevos cambios o mejoras en organización o gestión (87.8\%), en comparación con las empresas maduras (79.9\%), y nuevos cambios o mejoras en el aspecto comercial o de ventas (87.6\%), en comparación con las empresas maduras (81.8\%), aunque por nivel de importancia, las empresas jóvenes priorizan los cambios o mejoras en los procesos de producción (3.17), en comparación con las empresas maduras (2.87).

\section{Acceso al financiamiento}

El 18.5\% de las MIPYMES han solicitado líneas de financiamiento de entidades de crédito, el 30.3\% no han realizado la solicitud, porque no lo necesitan, y el 26.9\% no lo ha solicitado, porque se autofinancian. Adicionalmente, el $24.4 \%$ declara que no ha intentado acceder a líneas de financiamiento pese a necesitarlo, porque creen que no lo conseguirían.

$\mathrm{Al}$ analizar a las MIPYMES que han solicitado líneas de financiamiento, se aprecia que el 39.3\% de las solicitudes han sido aceptadas por las entidades de crédito en las mismas condiciones que en años anteriores y el 16\% han sido aceptadas, pero en peores condiciones. Mientras que solo un 29.2\% de los participantes declaró que la entidad de crédito no ha querido concederles el financiamiento o ellos no lo han aceptado; y, para un 15.5\%, la solicitud se encuentra en trámite. Esta información señala que el camino al financiamiento no ha sido más accesible para las MIPYMES durante la pandemia generada por la CoVID-19, a comparación de años anteriores o que tanto empresas como instituciones bancarias se muestran conservadoras en la aceptación y otorgamiento del crédito, respectivamente. 
Adicionalmente, se observa que, en cuanto al tamaño, las empresas medianas fueron aquellas que emitieron mayores solicitudes de financiamiento (30.2\%) en comparación con las microempresas (14.1\%) y, en cuanto al otorgamiento del crédito, se le ha concedido en mayor porcentaje, con las mismas condiciones que en años anteriores, a las empresas medianas (52.5\%), en comparación a las microempresas $(28 \%)$.

Asimismo, se observa que las empresas maduras (> 10 años) son aquellas que emitieron más solicitudes de crédito (21.5\%) y que se les concedió en las mismas condiciones que en años anteriores (45\%) en comparación con las empresas jóvenes ( $\leq 10$ años) con $14 \%$ y $28 \%$, respectivamente.

El análisis del acceso al financiamiento bancario se complementa con las condiciones de dicho financiamiento; se observa que la mayoría de las condiciones contractuales entre las entidades financieras y las MIPYMES se han mantenido estables. Los elementos que mejor han evolucionado son el volumen de financiamiento que ofrecen las entidades, con una puntuación media de 2.59, situándose a continuación el tiempo de respuesta de la entidad financiera (2.56), el plazo exigido para la devolución del financiamiento, así como el costo del financiamiento, ambos con 2.55. Los términos con una evolución menos favorable han sido las garantías exigidas (2.53) y las comisiones que se exigen (2.51).

\section{Indicadores de rendimiento}

Los indicadores de rendimiento más favorables para las MIPYMES mexicanas durante la pandemia, en relación con sus competidores más directos y el tamaño de la empresa, son a favor de la mediana empresa en los factores relacionados con ofrecer productos de mayor calidad (3.87\%), disponer de procesos internos más eficientes (3.74\%), adaptarse mejor a los cambios en el mercado (3.68\%), estar creciendo más (3.45\%) y ser más rentables (3.41\%). Por su parte, las microempresas tienen un menor absentismo laboral (3.02\%) que las pequeñas y medianas empresas; de igual forma, las microempresas cuentan con un mayor porcentaje de clientes satisfechos (3.99\%). Con relación a la satisfacción de los empleados, las empresas medianas $(3.67 \%)$ presentan un mayor porcentaje. 


\section{Referencias}

Amador, J., Cervantes, D., Rodríguez, A., Aranzazu, S., \& Serrano, C. (2020). Impacto del Covid-19 en la economía: la inacción es más peligrosa que la sobrerreacción, tanto para la salud pública como para la economía. BBVA Research. https://www. bbva.com/wp-content/uploads/2020/03/ImpactoCovid19Economia.pdf

Banco Mundial. (2020). Responder a la pandemia de COVID-19 y trabajar para una reconstrucción mejor. Banco Mundial. https://thedocs.worldbank.org/en/doc/ bb1b191f6b1bd1f932d0ddc5492987ec-0090012021/related/WBG-COVID-19Response-SP.pdf

Comisión Económica para América Latina y el Caribe. (2020). América Latina y el Caribe ante la pandemia del Covid-19. Efectos económicos y sociales. Informe especial COVID-19, (1), 1-15. https://repositorio.cepal.org/bitstream/ handle/11362/45337/4/S2000264_es.pdf

Instituto Nacional de Estadística y Geografía. (2020). Directorio Estadístico Nacional de Unidades Económicas. INEGI.

Instituto Nacional de Estadística y Geografía. (2021). Producto Interno Bruto de México durante el cuarto trimestre de 2020. Comunicado de prensa Núm. 157/21. https://www.inegi.org.mx/contenidos/saladeprensa/boletines/2021/ pib_pconst/pib_pconst2021_02.pdf

Sharma, P., Leung, T. Y., Kingshott, R. P. J., Davcik, N. S., \& Cardinali, S. (2020). Managing uncertainty during a global pandemic: An international business perspective. Journal of Business Research, 116(May), 188-192. 
FAEDPYME ha conformado en los últimos años una Red Internacional de Investigación sobre las MIPYMES, que facilita a los investigadores compartir recursos, proyectos y resultados de investigación que se utilizan en las instituciones de educación superior e investigación, en el campo de las disciplinas económicas y de la empresa. En México, la red está compuesta por la Universidad Autónoma de Baja California, la Universidad de Guanajuato (Campus Celaya-Salvatierra), la Universidad Autónoma de Nuevo León, la Universidad Estatal de Sonora (Unidad Académica Hermosillo), el Instituto Tecnológico de Sonora, la Universidad Tecnológica de Tamaulipas Norte y la Universidad Autónoma de Yucatán, así como otras universidades e institutos colaboradores. La finalidad de la red es mantener un espacio de colaboración, dentro de los ámbitos económico y social de las MIPYMES, tanto a nivel nacional como internacional, en orden a realizar conjuntamente actividades y trabajos de estudio, docencia e investigación, facilitar y promover el intercambio de información y del conocimiento, y el asesoramiento mutuo, así como desarrollar aquellos otros proyectos que resulten de interés común. Adicionalmente, FAEDPYME impulsa la relación entre la Universidad, la empresa y la Administración, conectando a la red de investigadores que trabajan en el campo de las MIPYMEs con su entorno empresarial y los agentes económicos y sociales. Todo ello con el objetivo de la aplicabilidad de la investigación, la formación y la transferencia del conocimiento. 


\section{(c) $(i)(9)(2)$}

Esta obra se edita bajo una Licencia Creative Commons

Atribución-NoComercial-Compartirlgual 4.0 Internacional.

IMPACTO ECONÓMICO DE LA CRISIS COVID-19

SOBRE LA MIPYME EN MÉXICO

Esta obra se terminó de producir en diciembre de 2021

Su edición y diseño estuvieron a cargo de:

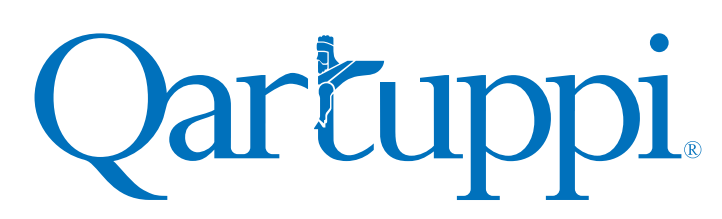

Qartuppi, S. de R.L. de C.V.

http://www.qartuppi.com 


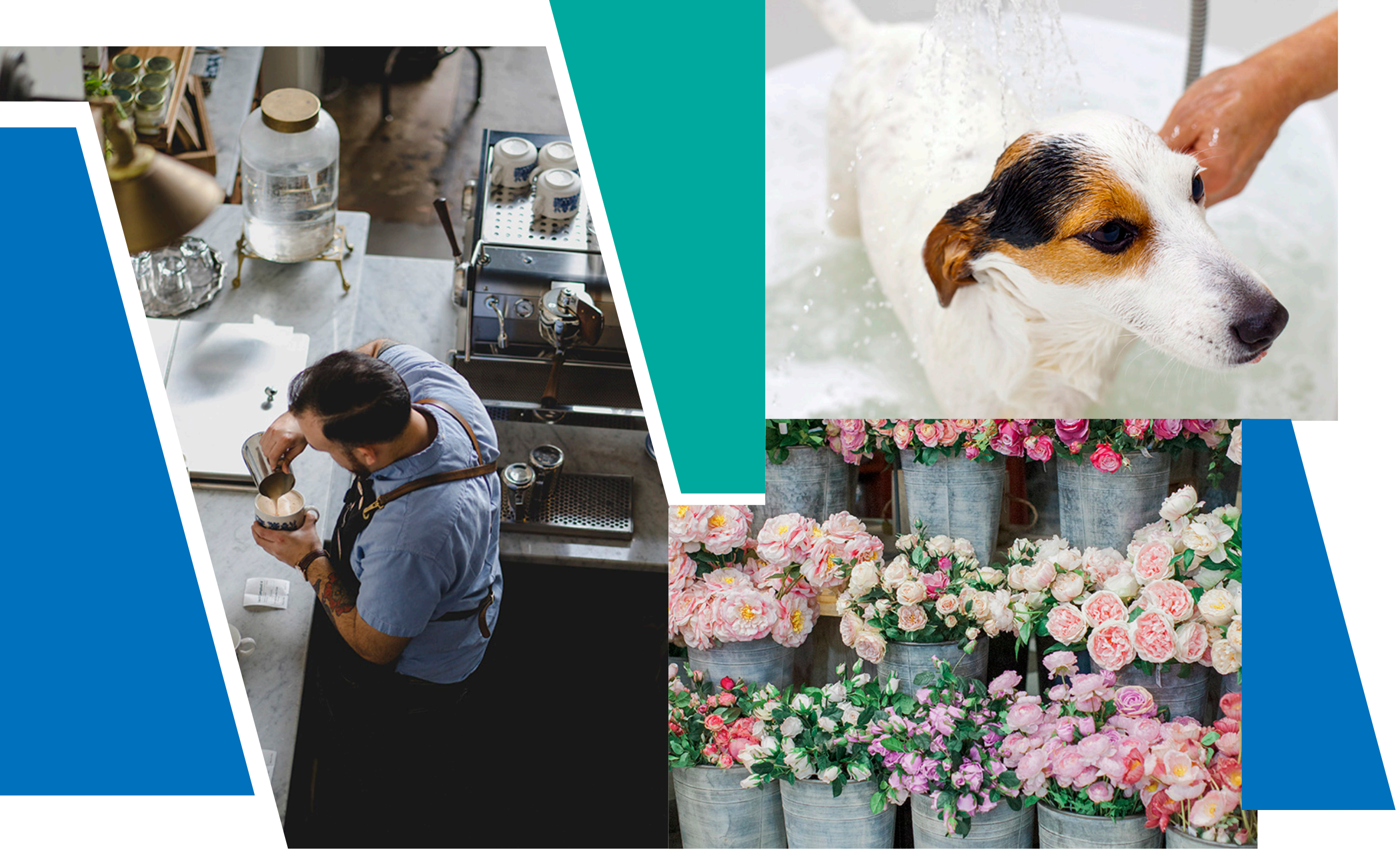

Esta obra muestra el impacto económico de la pandemia de la COVID-19 en el sector empresarial más vulnerable en México. Mediante el análisis de la información de 1417 MIPYMES mexicanas, se muestran los efectos de la pandemia sobre el empleo, las ventas, los indicadores económicos-financieros, los clientes y proveedores, las actividades operativas y estratégicas, la innovación, el financiamiento y el rendimiento, así como las expectativas de recuperación.
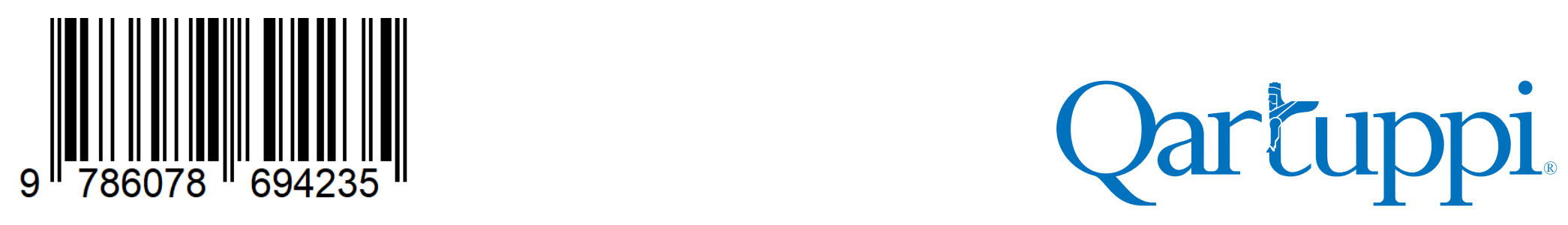